\title{
The most predictable patterns and prediction skills of subseasonal prediction of rainfall over the Indo-Pacific regions by the NCEP Climate Forecast System
}

\author{
Shaorou Dong ${ }^{1,2} \cdot$ Song Yang ${ }^{1,3,4}$ (1) $\cdot$ Xin Yan ${ }^{1,3} \cdot$ Tuantuan Zhang ${ }^{5} \cdot$ Yerong Feng ${ }^{6} \cdot$ Peng Hu H, $^{7,8}$
}

Received: 4 June 2019 / Accepted: 17 January 2020 / Published online: 5 February 2020

(c) The Author(s) 2020

\begin{abstract}
The most predictable patterns and prediction skills of subseasonal rainfall prediction for the Indo-Pacific regions are investigated using the daily hindcast product of the NCEP Climate Forecast System version 2. A maximum signal-to-noise empirical orthogonal function analysis indicates that on 30-60-day time scale the most predictable patterns exhibit a zonal dipole over the tropical Indian Ocean and the surrounding oceanic areas of the Maritime Continent in boreal winter and spring, associated with the eastward propagation of the Madden-Julian Oscillation. Differently, the most predictable patterns in boreal summer and autumn present a meridional dipole between a tropical belt (from the Arabian Sea, the Bay of Bengal, and the South China Sea to the western Pacific) and an equatorial belt (from the equatorial Indian Ocean to the equatorial Maritime Continent), related to the northward propagation of intraseasonal oscillation. Both the 30-60-day and 10-20-day patterns can be predicted at lead times around one half of their respective longest life cycles, with worst skills in summer. For the winter-spring 30-60-day patterns, the atmospheric drive on oceans plays an important role, and the corresponding winds at both upper and lower levels are consistent with the Gill response, suggesting the importance of the evaporation-wind feedback mechanism. During summer-autumn, cold sea surface temperature anomalies cause a change in land-sea thermal contrast, which is important for monsoon variations.
\end{abstract}

Keywords Subseasonal rainfall prediction $\cdot$ Most predictable pattern $\cdot$ Indo-Pacific regions

Song Yang

yangsong3@mail.sysu.edu.cn

1 School of Atmospheric Sciences, Sun Yat-sen University, 135 West Xingang Road, Guangzhou 510275, China

2 Guangdong Climate Center, Guangzhou, China

3 Guangdong Province Key Laboratory for Climate Change and Natural Disaster Studies, Sun Yat-sen University, Guangzhou, China

4 Southern Marine Science and Engineering Guangdong Laboratory (Zhuhai), Zhuhai, China

5 Institute of Environment, Energy and Sustainability, The Chinese University of Hong Kong, Hong Kong, China

6 Guangzhou Institute of Tropical and Marine Meteorology, Guangdong Provincial Key Laboratory of Regional Numerical Weather Prediction, CMA, Beijing, China

7 Center for Monsoon System Research, Institute of Atmospheric Physics, Chinese Academy of Sciences, Beijing, China

8 College of Earth and Planetary Sciences, University of Chinese Academy of Sciences, Beijing, China

\section{Introduction}

Tropical intraseasonal oscillation (ISO) is an important part of atmospheric variations. It mainly comprises the Madden-Julian oscillation (MJO; Madden and Julian 1971, 1972), which has a spectral peak around 30-60 days, and the quasi-biweekly oscillation (QBWO; Krishnamurti and Ardanuy 1980; Chen and Chen 1993, 1995), which has a characteristic period of 10-20 days. Many studies have been focused on the influences of ISO on tropical monsoon (Chan et al. 2002; Zhou and Chan 2005), Mei-yu front (Hung and Hsu 2008; Jia and Yang 2013), rainfall and sea surface temperature (SST) variations (Paegle et al. 2000; Maloney et al. 2014; Chen et al. 2015), the diurnal cycle of rainfall over the Maritime Continent (MC) (Rauniyar and Walsh 2010; Kanamori et al. 2013; Birch et al. 2016), tropical cyclone (Huang et al. 2011; Liang et al. 2011), and extreme drought/flooding and heat wave events (Jones 2000; Lu et al. 2012; Chen et al. 2016). Moreover, the two ISO modes exhibit a strong linkage (Kajikawa and Yasunari 2005) although they originate 
in different regions and propagate in different ways. Thus, improvement of the prediction skills for ISO variations or modes is helpful for improving rainfall prediction.

Dynamical prediction, characterized with overall improvement in operational climate forecast, has become indispensable in weather and climate forecasts in the past decades (e.g. Saha 2006, 2016). With improvements of initial condition and model resolution (Yang et al. 2009; Wen et al. 2012), and coupling process and data assimilation (Wang et al. 2001), the skills for seasonal prediction have become more promising. However, there are still deficiencies in models such as apparent systematic biases, errors of coupled process (Hannah et al. 2015), relationships between monsoons and other climate systems (Turner et al. 2005), etc. Furthermore, predictions show relatively poor skills for subseasonal variability and regional characteristics. Apparently, many models have difficulties in capturing the robust variability of the ISO. The skills for subseasonal prediction and potential predictability with dynamic models have raised much attention in both academic and operational sectors (Waliser et al. 2003; Reichler and Roads 2005; Seo et al. 2009; Wang et al. 2014).

On the one hand, the subseasonal prediction that is focused on the extension from weather phenomena to seasonal mean state is strongly associated with both boundary forcing and initial conditions, and thereby is full of challenges (Liu et al. 2015). On the other hand, the skill of subseasonal prediction is different remarkably among various models, although it also depends on measuring methods and the variables analyzed. For example, fj prediction of rainfall is more challenging than prediction of atmospheric circulation. Additionally, the inherent predictability of MJO can creep up to about 30-40 days, and the actual skill attains 10-20 days and even 10-30 days when ensemble methods, in which the advantage of having a hindcast climatology for removing model bias is considered, are applied (Wheeler and Hendon 2004; Lin et al. 2008; Neena et al. 2014; Hannah et al. 2015). Both the MJO and QBWO modes may be potentially predictable at lead time longer than one-half of their respective life cycles (Wang et al. 2009). In spite of certain deficiencies, climate models exhibit skills in predicting the major characteristics of ISO.

For a better understanding of subseasonal prediction, an analysis of the dominant modes identified by the so-called maximized signal-to-noise empirical orthogonal function analysis (MSN EOF; see next section for detail) seems helpful. On seasonal time scale, the most predictable patterns of monsoons (Liang et al. 2009; Zuo et al. 2013), low-level circulation (Zhang et al. 2018a, b), and the SST patterns of the tropical Atlantic (Hu and Huang 2007) and the Indian Ocean (IO) (Zhu et al. 2015) have been depicted by this method. Jia et al. (2013) have focused on the prediction skills for the eight dominant QBWO modes from a prospective of global patterns (see Wang et al. 2008); however, the most predictable patterns of regional rainfall on subseasonal time scale are still unseen. Besides, previous studies on ISO are mainly concentrated on summer and winter seasons, with little attention on the transitional seasons. Due to the strong seasonal and regional features of the ISO (Yang and Wang 2008; Wang and Xie 1997), it is necessary to discuss the regional modes of subseasonal prediction for all seasons. The Indo-Pacific Ocean is one of the mainly-concerned regions since it is one of the key regions for both QBWO sources and MJO phases. For example, tropical ISO mostly propagates eastward in the eastern hemisphere, and the IndoPacific Ocean is the region where ISO is initiated actively (Wang and Rui 1990).

In light of the above aspects, here we conduct an investigation into the most predictable patterns and prediction skills of regional rainfall over the Indo-Pacific domain for subseasonal time scale and their evolutions. Observational data, model output, and analysis methods are introduced in Sect. 2. Skills of subseasonal prediction for rainfall patterns and regional characteristics, related large-scale features, and its lead-time dependence are examined in Sects. 3 and 4. The mechanisms for pattern distributions and diverse skills are also discussed in Sect. 4. A summary and discussion of the results obtained are shown in Sect. 5.

\section{Data and methods}

The National Centers for Environmental Prediction (NCEP) Climate Forecast System version 2 (CFSv2) is a fully coupled dynamic prediction system, and it consists of the NCEP Atmospheric Global Forecast System with T126 resolution in the horizontal and 64 sigma layers in the vertical as the atmospheric model (Moorthi et al. 2001). Its land component is the NCEP, Oregon State University (OSU), the Air Force, and the Hydrologic Research Laboratory land model (Ek et al. 2003) and the ocean component is the Modular Ocean Model version 4.0 from the NOAA Geophysical Fluid Dynamics Laboratory (GFDL) (Griffies et al. 2003). The daily rainfall output from the retrospective forecasts with 45-day integration is analyzed. The hindcast runs were initialized from every 0000, 0600, 1200, and 1800 UTC cycle from 1999 to 2014, and the longest lead time for a target day is 44 days. The 0 -day lead represents that the model runs were initialized on the current day, the 1-day lead for the forecasts initialized on the previous day, and the 44-day lead for 44 days ago. The hindcast output from 2011 to 2014 is calculated consistently with that from 1999 to 2010 (with 29 February in the leap years omitted), and totally 44 lead days are obtained. For convenience, LD0 represents the smoothed output of 0-day lead, 1-day lead, and 2-day lead; LD1 represents the smoothed output of 1-day lead, 2-day lead, and 
3-day lead; ... and LD42 represents the smoothed output of 42-day lead, 43-day lead, and 44-day lead. The 10-20-day and 30-60-day Lanczos band-pass filters (Duchon 1979) are applied on daily rainfall anomalies to obtain the time series of ISOs. Pentad mean and three-day mean are used for 30-60-day patterns and 10-20-day patterns after filtering, respectively.

The observational data sets applied include the daily rainfall data with a horizontal resolution of $1^{\circ}$ from the Global Rainfall Climatology Project (GPCP; Adler et al. 2003), and the daily wind data with a horizontal resolution of $1^{\circ}$ from the European Centre for Medium-range Weather Forecasts (ECMWF) (Dee et al. 2011). The daily-interpolated outgoing longwave radiation (OLR) data, also with a horizontal resolution of $1^{\circ}$, from the NOAA Climate Data Record (CDR) program for satellites (Liebmann and Smith 1996; Lee et al. 2007; Lee 2014) and the daily SST data with a horizontal resolution of $0.25^{\circ}$ from the NOAA optimally interpolated (OI) SST (Reynolds et al. 2007) are employed as well.

The MSN EOF, developed by Allen and Smith (1997), is a method to derive the patterns that optimize the signal-tonoise ratio from all ensemble members (Venzke et al. 1999; Huang 2004) when the number of ensemble members is limited. The ensemble mean of the prediction system comprises two portions: one is the forced portion associated with the prescribed external boundary conditions and the other is the random part contributed by unpredictable internal noises. Because of the memories contained in all initial conditions, the consistency of evolution among different ensemble members from a model is found. However, the size of ensemble members is limited and therefore the effect of internal noises coming from the deviations within ensemble members is not negligible. The MSN EOF contributes to extraction of the forced part, namely, the predictable signals. At the same time, it helps to minimize the effects of noises among different ensemble members. Thus, higher variances of the MSN EOF patterns denote higher predictability. The first mode extracted by this method, the most predictable pattern, shows the maximized ratio of the variance of ensemble mean to the deviation among ensemble members. Previous studies have successfully applied the MSN EOF to derive predictable patterns of targeted variables over different regions (Venzke et al. 1999; Huang 2004; Hu and Huang 2007; Liang et al. 2009; Zuo et al. 2013; Zhu et al. 2015; Zhang et al. 2018b). Similar to the conventional EOF modes, the MSN EOF predictable patterns also show a spatial-temporal distribution, and the relationship between the observed projection $\mathrm{PC}$ and ensemble mean PC denotes the skill of MSNEOF modes. Unlike conventional EOF, the MSNEOF involves the process to transfer red noise to white noise, which helps to reduce the effect of "noise" that tends to cancel each other within individual members but still makes a difference when ensemble size is relatively small.

More details are as followed: matrix $X_{M}=X_{P}+X_{R}$, in which $X_{M}$ represents ensemble mean, $X_{P}$ predictable signal, and $X_{R}$ unpredictable random component; and $X_{P}$ and $X_{R}$ are assumed uncorrelated with each other. Despite the counterbalance of noise within individual ensemble members, the residual, namely $X_{R}$, is not negligible. Thus the covariance matrix of ensemble mean matrix $C_{M}$ can be divided into two parts: the signal and residual noise covariance matrices. In order to deduct the spatial covariance of noise and derive the eigenvectors of the above signal covariance matrix, "prewhitening" is involved in the MSN EOF by a transformation matrix $(F)$ to transform the internal variation to white noise. This transformation matrix is derived by the first $\mathrm{K}$ weighted EOF patterns of the within-ensemble deviation matrix. The 1st column vector (the optimal filter) from the matrix of eigenvectors of $F^{T} C_{M} F$ maximizes the ratio of the variances of ensemble mean to the deviations among ensemble members due to noise filters. The PC of the MSN EOF is derived by projecting $X_{M}$ onto the above corresponding column vector and the predictable pattern of the MSN EOF is obtained by projecting $X_{M}$ onto the corresponding MSN PC. The 1st pattern is thus named the most predictable pattern, and the 2nd pattern is called the second most predictable pattern for the same reason.

\section{Patterns and skills}

\subsection{Most predictable patterns of 30-60-day time scale}

The first and second modes of conventional EOFs of the regional rainfall during winter and spring on 30-60-day time scale are shown in Fig. 1. The standard deviations of 30-60-day filtered rainfall for the winter half of the year (Fig. 1a, d) offer an overview of the spatial characteristics of convective activity associated with the MJO. Active convection centers appear along the equator during the winter half of the year, with more extensive distribution further to the north in spring. Conspicuous active centers occur over the eastern equatorial IO, east of the Philippine Islands, and north of Australia. For this conventional EOF analysis, the first and second modes explain $17.91 \%$ and $11.43 \%$ (17.72\% and $9.18 \%$ ) of the total variances in winter (spring), respectively (Fig. 1b, c, e, f). All the PCs contain obvious subseasonal variability (not shown). Similar patterns, which mainly imply a zonally out-of-phase variation over the eastern tropical IO and the western tropical Pacific, can be seen from the first modes during the boreal winter half of the year. This 

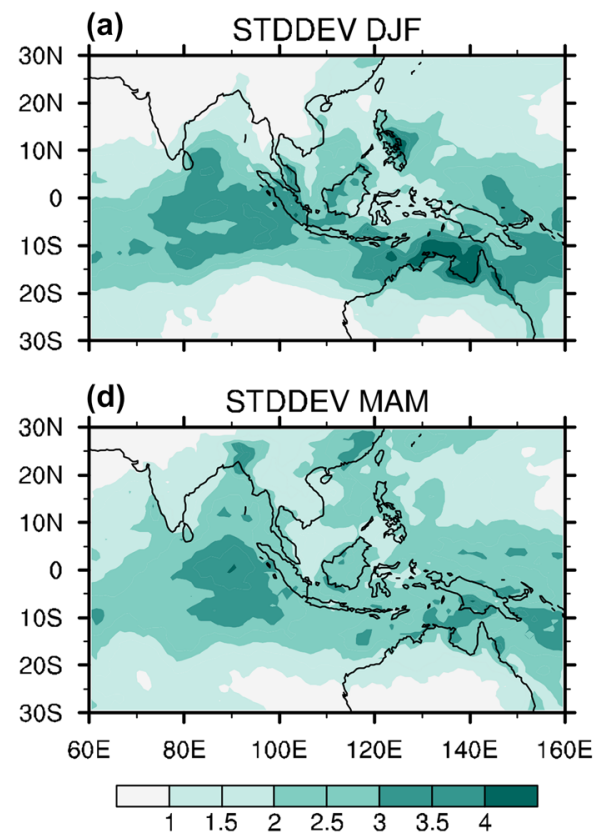
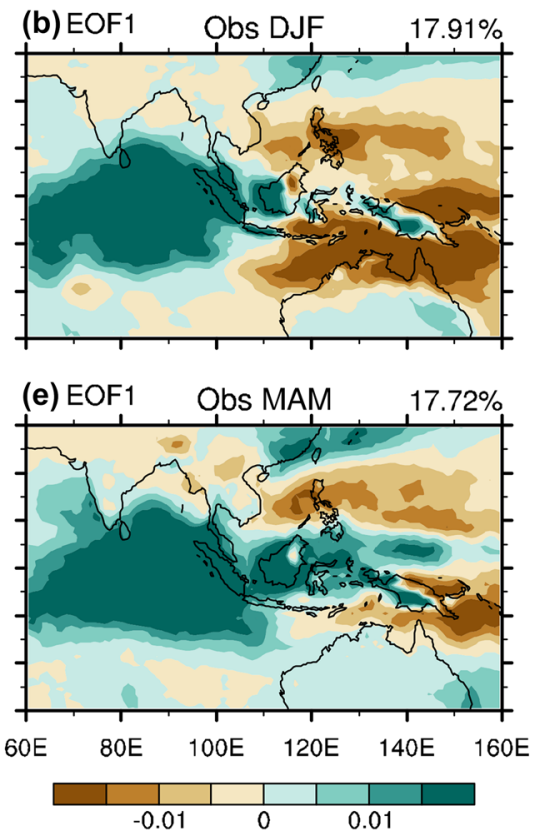
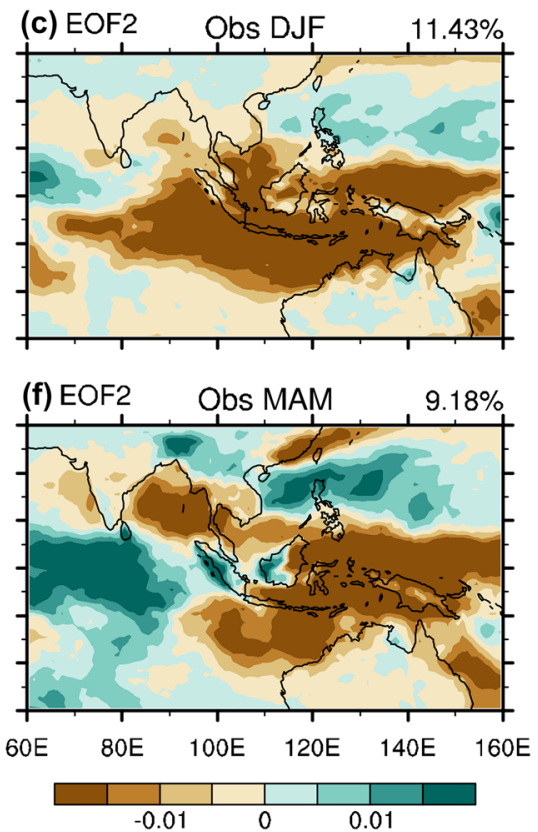

Fig. 1 Standard deviation of rainfall subseasonal variations on 30-60-day time scale in a winter and d spring for period of 19992014. Conventional EOF modes of observed rainfall ( $\mathrm{mm} /$ day) over the Indo-Pacific regions on 30-60-day time scale for $\mathbf{b}$ first mode in winter, $\mathbf{c}$ second mode in winter, $\mathbf{e}$ first mode in spring and $\mathbf{f}$ second mode in spring
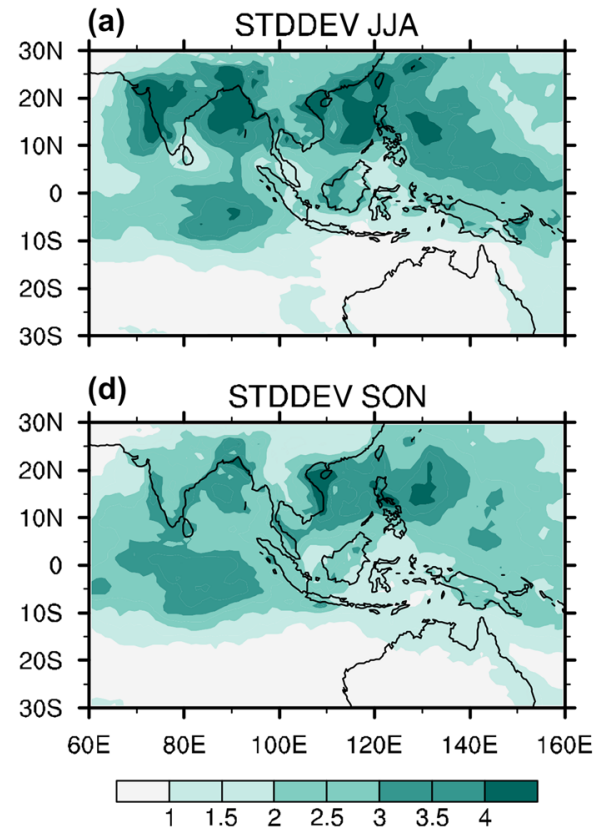
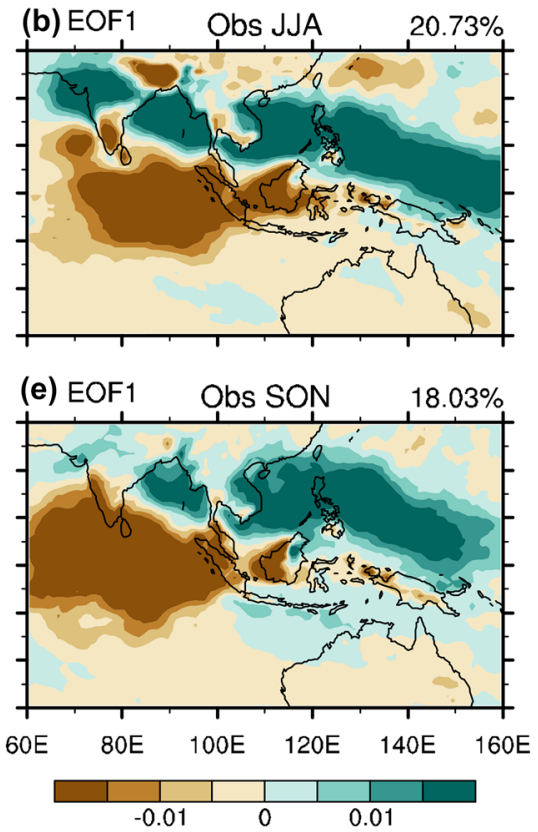
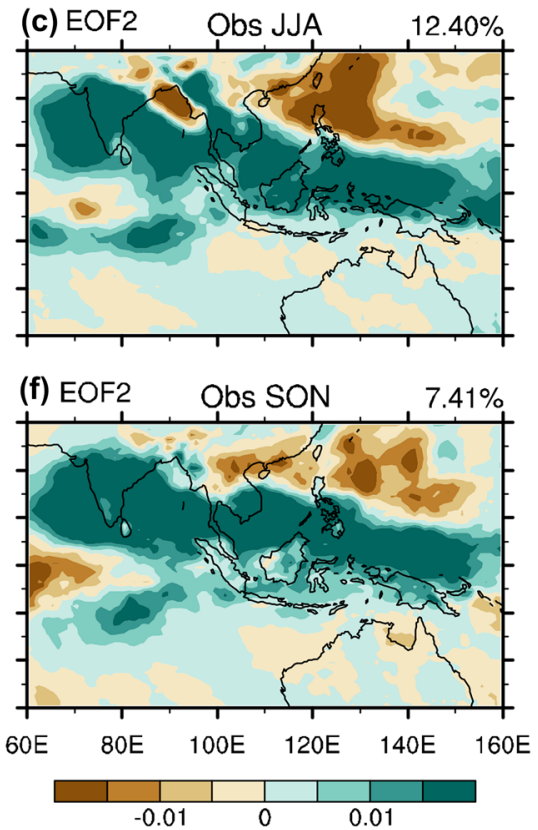

Fig. 2 Standard deviation of rainfall subseasonal variations on 30-60day time scale in a summer and d autumn for period of 1999-2014. Conventional EOF modes of observed rainfall (mm/day) over the
Indo-Pacific regions on 30-60-day time scale for $\mathbf{b}$ first mode in summer, $\mathbf{c}$ second mode in summer, $\mathbf{e}$ first mode in autumn and $\mathbf{f}$ second mode in autumn distribution characteristic is reserved in the second mode in spring, although it also denotes a zonal dipole within $10^{\circ}$ of the equator. However, a consistent variation between the
MC and the nearby areas is depicted by the second mode of winter. 
Figure 2 shows similar magnitude of variance for the dominant modes in summer and autumn, compared with Fig. 1, which respectively explain $33.13 \%$ and $25.44 \%$ of the total variance. Similar spatial distributions exhibit a strong meridional out-of-phase variation on subseasonal time scale during the boreal summer half of the year. The first modes of the two seasons mainly show dipoles over the IO, while the second modes primarily exhibit dipoles over the western Pacific. The main centers of convective variability on 30-60-day time scale shift away from the equator to $10-20^{\circ} \mathrm{N}$ during the summer half of the year (compare Fig. 2a, d with Fig. 1).

The variance contribution of the most predictable patterns in winter at different leads is around 30\% (Fig. 3), which is higher than that given by conventional EOF1 (Fig. 1). Indeed, the MSN EOF effectively captures the most predictable pattern from the noise-embedded variation. Compared with Fig. 1a, the patterns of MSN EOF1s at different leads
30-60D DJF

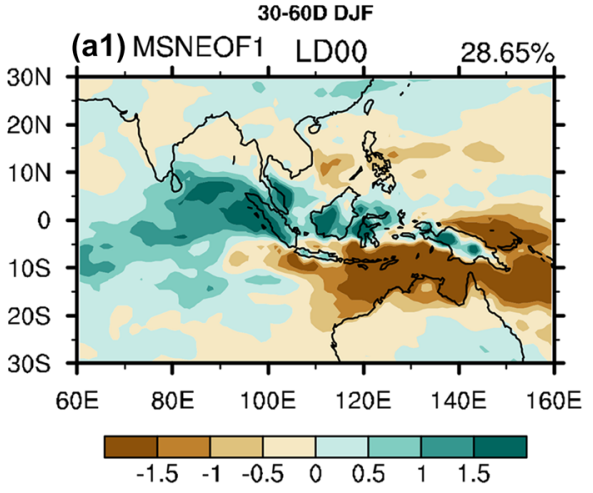

(a2) PC1 R=0.941 R1=0.975

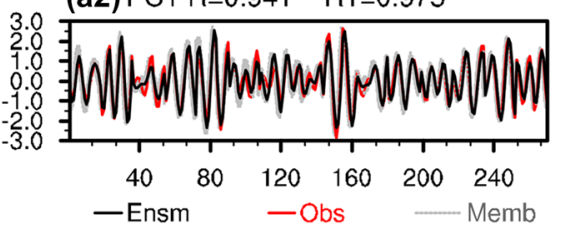

30-60D DJF

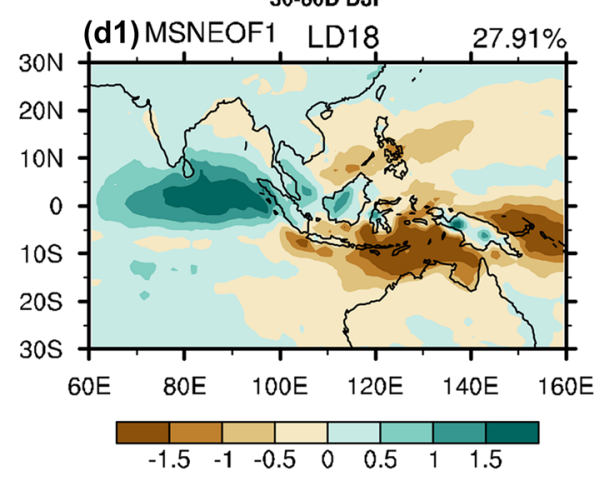

(d2) PC1 R=0.499 R1=0.936.781 0.674

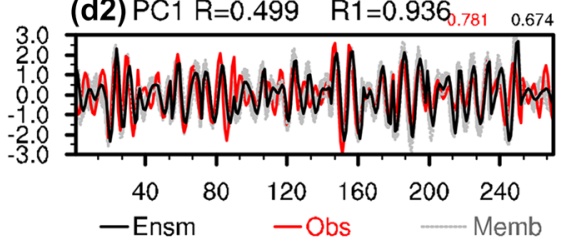

30-60D DJF

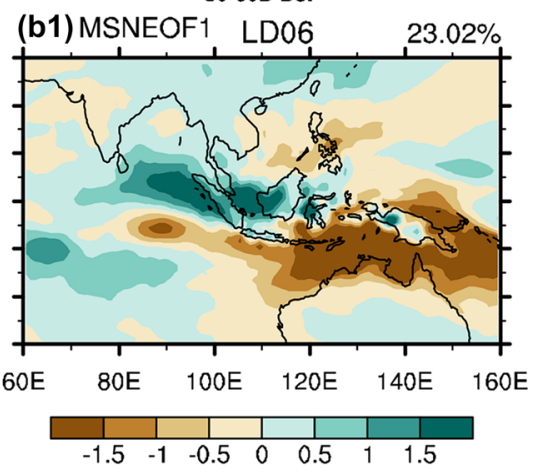

(b2) PC1 $R=0.802 \quad R 1=0.96 Q_{8.867} \quad 0.798$

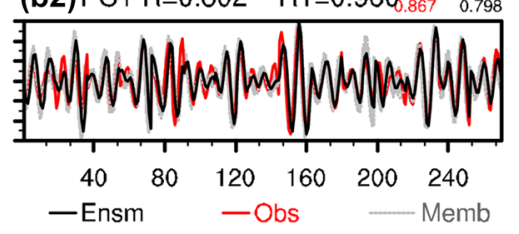

30-60D DJF

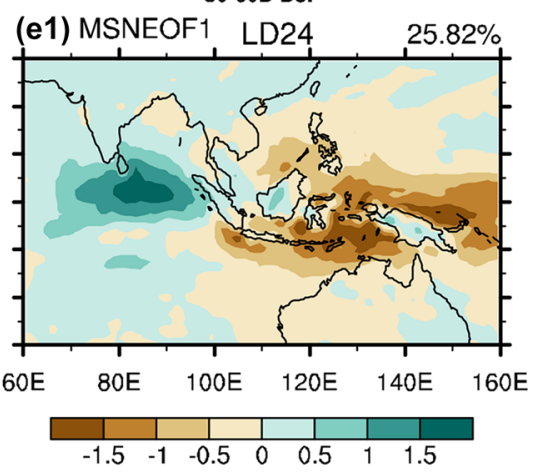

(e2) PC1 $\mathrm{R}=0.225 \quad \mathrm{R} 1=0.913_{.924} \quad 0.830$

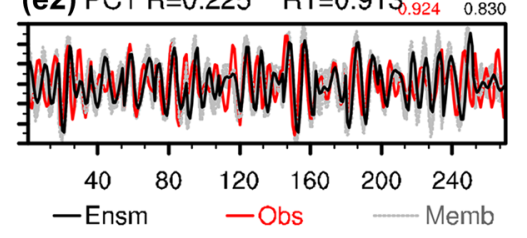

30-60D DJF

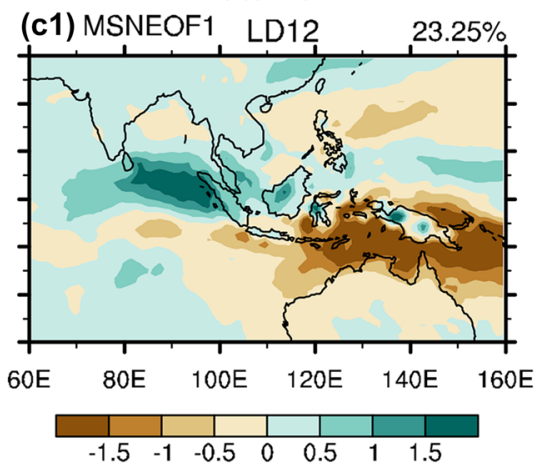

(c2) PC1 R=0.702 R1=0.951 $1_{0.853} \quad 0.644$

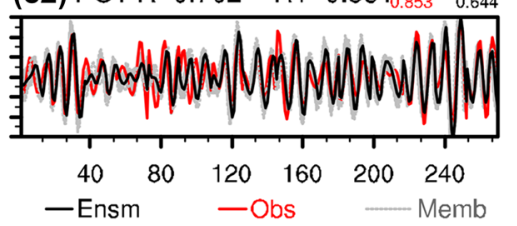

30-60D DJF

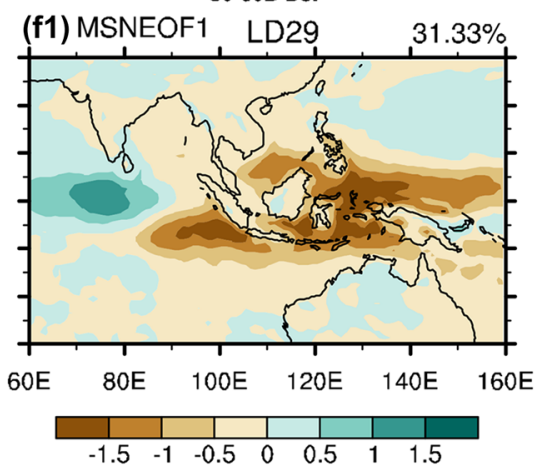

(f2) PC1 R=0.216 R1=0.914 $0.794 \quad 0.740$

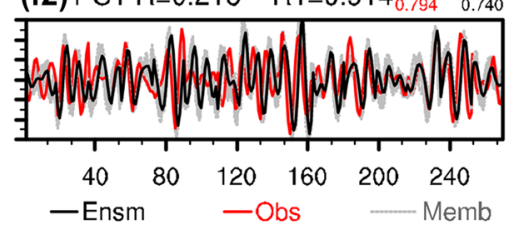

Fig. 3 First MSN EOF modes and PCs of rainfall (mm/day) predicted by the CFSv2 for lead days of $0,6,12,18,24$, and 29 in winter on 30-60-day time scale. The solid black lines represent the PCs of ensemble means and the dashed grey lines represent the PCs of different ensemble members while the solid red lines represent the PCs that are computed by projecting the observed rainfall onto the spatial distribution of the MSN EOF1. R represents the correlation coefficient between the solid red line and the solid black line, and R1 represents the averaged correlation coefficient among ensemble members 
consistently exhibit a generally zonal dipole as mentioned above, except for the relatively weak centers over the southern equatorial IO. The two main centers over the northern IO and to the north of Australia result in a tilted dipole from LD0 to LD24, which is consistent with the evolution of equatorial eastward (EE) propagating mode [an equatorially trapped mode for tropical intraseasonal convection anomaly whose center is confined to a narrow equatorial belt between $15^{\circ} \mathrm{S}$ and $15^{\circ} \mathrm{N}$, e.g., evolution of the centers from JAN 26 to FEB 19 1985; see Fig. 1 of Wang and Rui (1990)]. After LD26, the pattern resembles the mature phase of the EE mode [pentad 6 in Wang and Rui (1990)]. The model provides a decent prediction of both variability and magnitude of the variations at short leads. Moreover, the pattern at LD29 is still predictable, with R (the correlation coefficient between the ensemble-mean PC and the projecting observation PC) significantly exceeding a certain confidence level. R1, the averaged correlation coefficient among different ensemble members, testifies that the influence of noise becomes more outstanding at longer leads due to limited size of ensemble members, which results in uncertainty of the signals at long leads. Although the spread of members is definitely larger with increasing lead time and small ensemble size, after applying the MSN EOF analysis, R1 surprisingly remains at a high confidence level of $0.95 \%$ and only drops slightly at longer leads. The sustaining high R1 implies that the most predictable pattern in winter is quite robust at different leads, and the model can well capture the leading modes of ensemble-mean variation by the MSN EOF analysis.

The MSN EOF1s in spring explain at least $20 \%$ of the total variance at short leads and around 30\% at longer leads (Fig. 4). The pattern is unstable before LD7 due to its sensitivity to initial memory. After one week's lead, initial memory decays and low-frequency component becomes pronounced. The pattern is stable from LD8 to LD28 in spring, exhibiting similarity to that in winter (compared with Fig. 3). The out-of-phase centers can be found from the equatorial IO and the main portion of the MC to the South China Sea (SCS), the eastern Bay of Bengal (BOB), and to the north of Australia before LD31, as shown in Fig. 4a-e. Such most predictable pattern is consistent with the evolution of $\mathrm{N}(\mathrm{S}) \mathrm{E}$ mode [a similar track like the EE mode, but the convective center turns either northeast or southeast branch when passing through the MC, e.g. evolution of the centers from 6 to 25 APR 1985; Fig. 3 of Wang and Rui (1990)]. According to Fig. 4, there are two branches in the most predictable pattern during spring, with one occupying from the eastern BOB, the SCS to the western subtropical Pacific and the other occupying the north of Australia. These two branches are separated by stretched tips of the center extending from the equatorial IO to the New Guinea. Such features of spatial distribution are more obvious in spring than in winter. Moreover, the most predictable pattern in spring is similar to that in winter, except the two stronger centers over the eastern BOB and the SCS (associated with monsoon onset) and the relatively weaker southern branch to the north of Australia. (The southern branch is stronger in boreal winter than in spring due to the influence of the Australian summer monsoon.) Similarly, R drops with increasing lead time, while $\mathrm{R} 1$ maintains at a high level. The robust most predictable pattern in spring changes after LD31 from a zonal dipole into another type, a consistent variation type. A similar pattern shift can be found in the boreal winter around LD25 as shown in Fig. 3.

In short, the most predictable patterns during both winter and spring show a tropical zonal dipole that mainly implies the eastward propagation of MJO, a feature will be further discussed in Sect. 4. This characteristic of the dominance of MJO mode is consistent with the result of Wang and Xie (1997).

The most predictable patterns in summer and autumn are very similar with each other (thus autumn features not shown) and they remain stable at all leads with relatively high R1 values. (The first modes of summer and autumn explain $\sim 40 \%$ of the total variance at short leads and even $50 \%$ at longer leads.) The discrepancies of variance contribution between MSN EOF1 and MSN EOF2 are quite larger during the boreal summer half of the year, compared with those during the winter half of the year (Figs. 3, 4). The Asian monsoon is considered to be the world's most prominent monsoon component. Under the background of monsoon onset and demise, active intraseasonal convective systems play an important role in climate prediction especially for the most predictable patterns in summer and autumn, which contributes to the high value of variance. Moreover, ensemble spread (discussed later), associated with the unpredictable "noise", is controlled when the MSN EOF is applied, illustrating the high variance of the most predictable patterns in summer and autumn. There exist two outof-phase belts in both summer and autumn: one is between the Arabian Sea, the BOB, the SCS, and the western Pacific, and the other is from the equatorial IO to the MC as shown in Fig. 5 (autumn not provided). The out-of-phase centers over the IO, the Arabian Sea, and the BOB are mainly associated with the Indian monsoon, while the ones over the SCS and the MC are related to the East Asia summer monsoon. These spatial distributions are consistent with the equatorial eastward movement of the northward moving (EN) mode, a combination of the major equatorial eastward movement and the northward movements over the Indian and western Pacific monsoon regions, e.g., AUG 29-SEP 21976 [Fig. 4 in Wang and Rui (1990)]. R drops more quickly with increasing lead time in summer, compared with the other three seasons. However, the values of R1 in both summer 

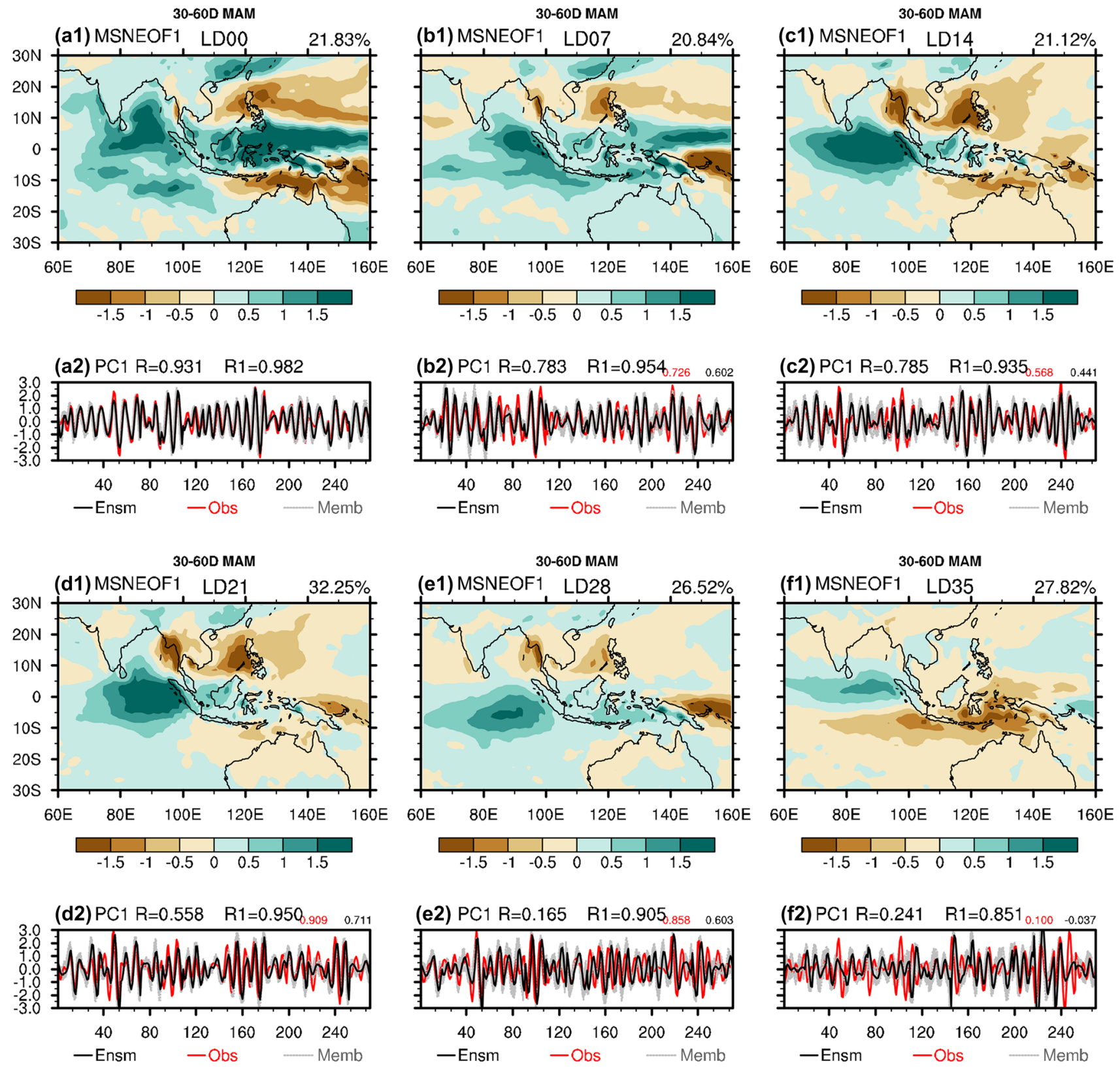

Fig. 4 Same as Fig. 3 but for lead days of 0, 7, 14, 21, 28, and 35 in spring

and autumn remain high at all leads, which is consistent with the stable patterns during the summer half of the year.

In summary, the most predictable patterns during both summer and autumn show a meridional dipole. This feature mainly implies a northward propagation of the boreal summer ISO (with a period of 30-60 days).

\subsection{Skills and pattern shift}

Focusing on the spatial-temporal evolution of intraseasonal activities (Sperber et al. 1997; Waliser et al. 2003), previous studies showed skill versus lead time of MJO by anomaly correlation and indicated prediction skills of 10 days for rainfall and 3 weeks for zonal wind (Jones and Schemm 2000; Jones 2000; Reichler and Roads 2005; Wang et al. 2014). Seo et al. (2007) calculated the intraseasonal anomaly correlation and time evolution for each phase of U200 (Seo et al. 2005) and compared four empirical forecast schemes including the CFS dependence on PC1 and PC2, finding a correlation skill extension to 15 days for both PCs (Seo et al. 2009). Waliser et al. (2003) also stressed the influence of ensemble spread on prediction skills of models. Figure 6 shows the skills of the predictable patterns of rainfall over the Indo-Pacific regions on 30-60-day time scale, and it 

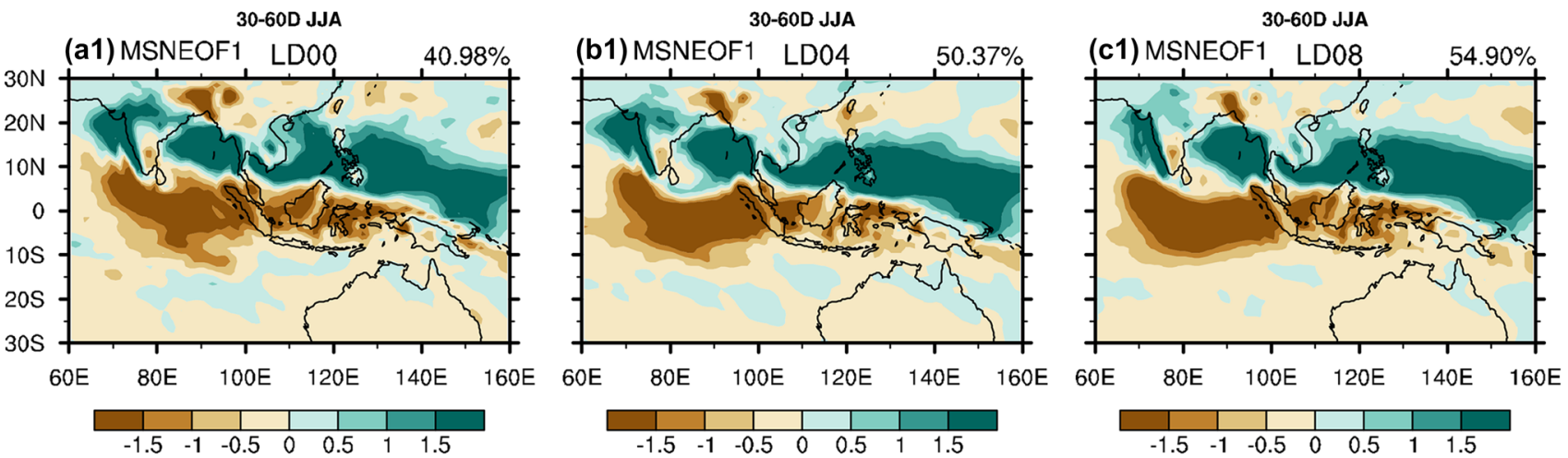

(a2) PC1 R=0.941 R1=0.985
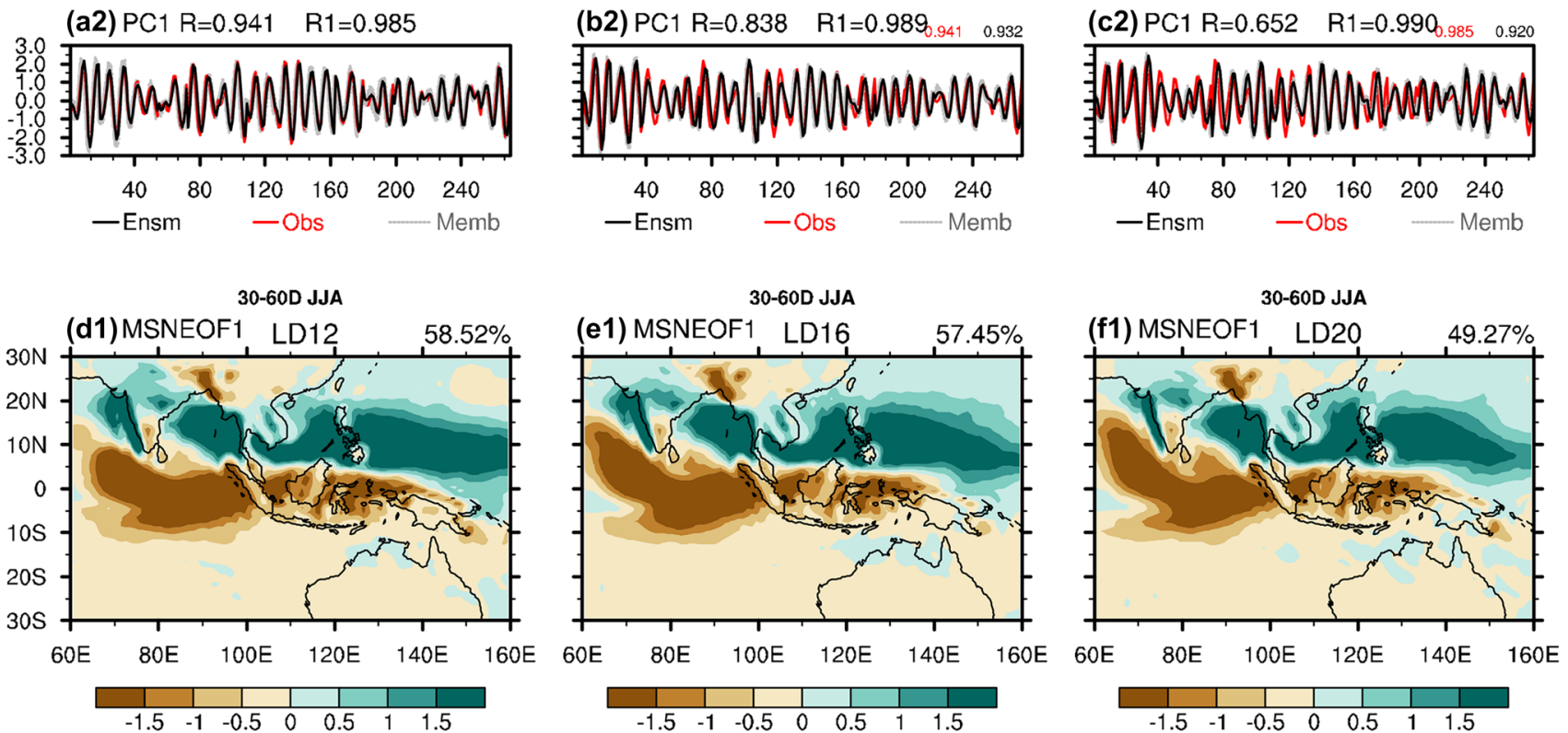

(d2) PC1 R=0.512 R1=0.988 ${ }_{.962} \quad 0.890$
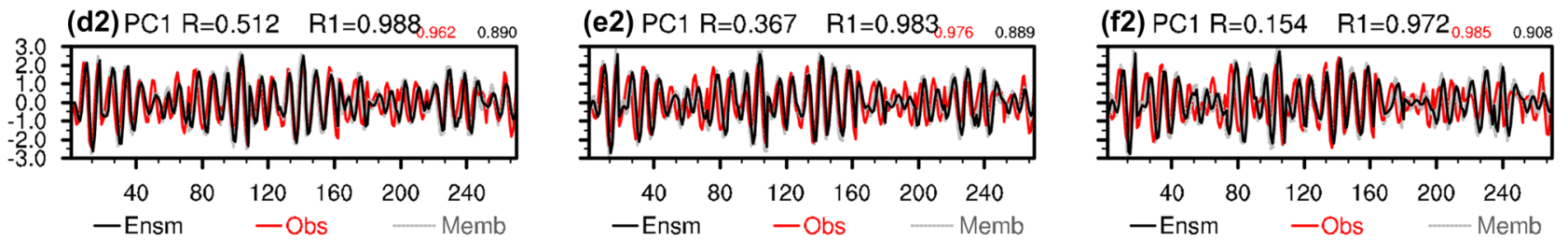

Fig. 5 Same as Fig. 3 but for lead days of 0, 4, 8, 12, 16, and 20 in summer

indicates that both MSN EOF1 and MSN EOF2 are similar with observations. As expected, skills decrease with increasing lead time. The model exhibits the lowest skill around 20 days in summer (Fig. 6a), for which the prediction is initiated from mid-April to mid-June when monsoon becomes active. This feature is consistent with the result of Lin et al. (2008) and Rashid et al. (2011). The most dominant patterns can be predicted about 30 days in advance for winter and the two transitional seasons. Within the leads of two weeks, these three seasons show high correlations above 0.6. Compared with the MSN EOF1, the MSN EOF2 exhibits relatively lower predictability at the same leads (Fig. 6b).
As discussed above, only the predictable patterns in winter and spring suffer from a pattern shift at long leads. The shift of the most predictable pattern in winter occurs after LD24 while the one in spring occurs after LD28, changing from a zonal dipole to uniform variation (Figs. 3, 4). Figure 7 testifies the similarity between the predictable patterns and the observed EOF modes during the winter half of the year. In winter, the solid blue line maintains at a high level above 0.6 at short lead, implying that the most predictable pattern matches the first EOF mode of observed rainfall on 30-60-day time scale quite well before LD25 (Fig. 1b). A sudden drop of the blue line occurs around LD25, and 
(a) M1 Cor. Pre. 30-60D

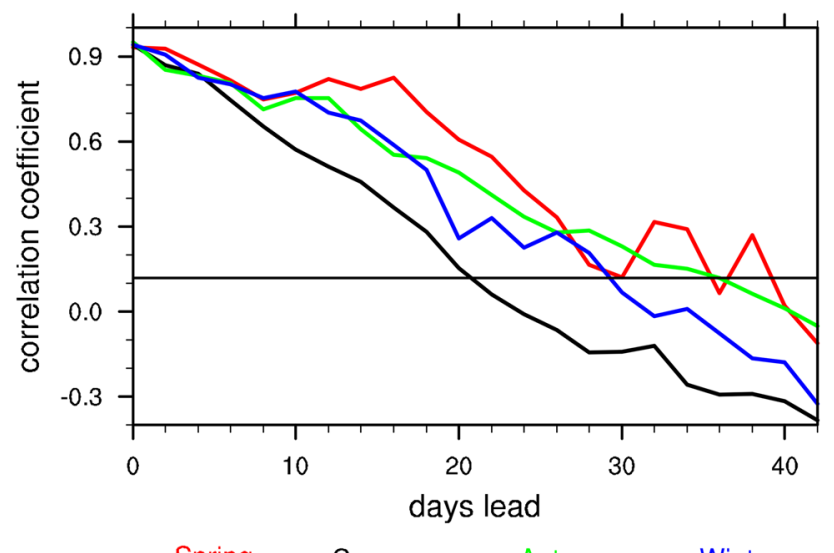

(b) M2 Cor. Pre. 30-60D

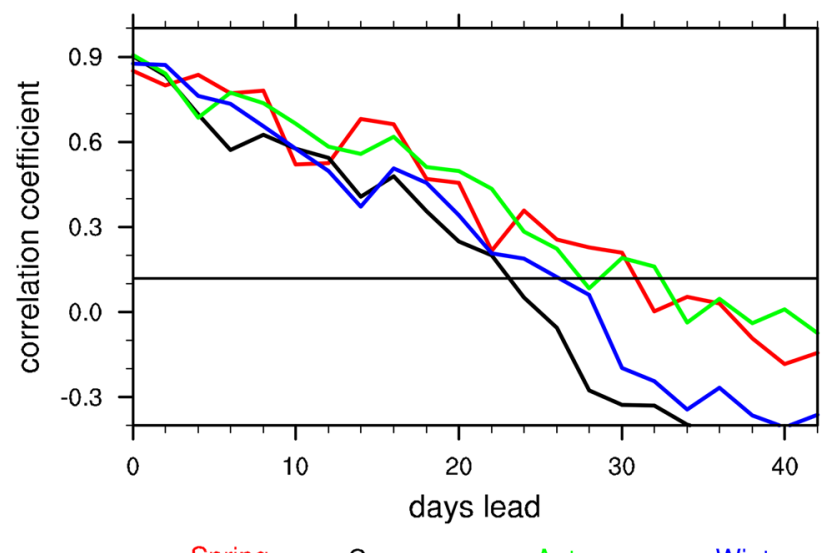

-Spring -Summer —Autumn -Winter

Fig. 6 Correlation coefficients between ensemble-mean PCs and projected PCs (computed by projecting the observed rainfall upon the corresponding MSN EOF modes) for a MSN EOF1 and b MSN EOF2 on 30-60-day time scale. The black straight line represents the correlation coefficients at the $95 \%$ confidence level

the correlation between the most predictable pattern and the observed EOF 2 (Fig. 1c) becomes comparatively pronounced (the solid red line ascends largely and surpasses the blue line), which implies a pattern shift of the most predictable pattern from observed EOF 1 to EOF 2. Accordingly, the MSN EOF2 in winter also exhibits a pattern shift from observed EOF 2 to EOF 1 around LD25 (dashed pink line replaced by dashed black line, Fig. 7a), and such a transformation of pattern can be seen from Fig. 8a-c, characterized by a transformation from the consistent variation over the $\mathrm{MC}$ to a tropical zonal dipole. Compared with the pink line, the higher value of the blue line suggests higher predictability of the MSN EOF1 than of the MSN EOF2, which is consistent with the result in Fig. 6.

In spring, the shift of the most predictable pattern from observed EOF 1 (Fig. 1e) to EOF 2 (Fig. 1f) can be found around LD30 as shown in Fig. 7b, which is consistent with the transformation seen from Fig. 4. However, the pattern shift around LD30 in spring is not as obvious as that in winter, given that the pattern correlation between MSN EOF1 and observed EOF2 (solid red line after LD30 in Fig. 7b) is only around 0.4 , significantly lower than the 0.8 in winter (Fig. 7a). Moreover, the MSN EOF2 in spring resembles both observed EOF 1 and EOF2 as shown in Fig. 8e, f. In summary, the pattern shift confined to modes 1 and 2 occurs only in winter and spring at long leads.

According to Fig. 9a, the close relationships between ensemble members and ensemble mean for modes 1 and 2 in winter both drop suddenly after LD20 and reach the lowest value around LD25 when a pattern shift arises, but the relationships become stronger again, a feature which is more remarkable than that in spring around LD30. During summer and autumn (Fig. 9d), the spread of ensemble members is quite small with highly maintained values of correlation coefficients around 0.9 at all leads. The low value of y axis in Fig. 9 denotes high spread within ensemble members and vise versus. Both EOFs and PCs show the same result, implying that the pattern shift during the winter half of the year as shown in Figs. 7 and 8 is closely related to the large spread of ensemble members. That is, the large spread of ensemble members results in a pattern shift during winter and spring. In fact, the pattern shift occurs more apparently during the winter half year in conventional EOF modes where the ensemble deviation is not under controlled (figures not shown). Without application of the MSN EOF, both the ensemble spread and the pattern shift are obvious in winter and spring. Waliser et al. (2003) pointed out that the mean forecast error and the mean signal tend to be equal at about 20-30 days over the western Pacific and the impact of ensemble spread on predictability, which possibly explains why pattern shift occurs around 20-30 days. Generally, ensemble spread is one of the main sources of errors besides systematic bias and initial condition. Thus, Fig. 9 explains the possible mechanism of pattern shift as discussed above. Although the instability of signals still slightly grows up with lead time, the MSN EOF helps to confine the spread of ensemble members and reduce the influence of noise (Fig. 9c, f).

\section{Related large-scale climate variation}

Figures 10 and 11 show the patterns of regression of SST, OLR, and wind fields against the ensemble-mean PC1 on 30-60-day time scale for winter and summer, respectively. Since the most predictable patterns of the Indo-Pacific rainfall are similar between winter and spring, and between summer and autumn, the regression patterns for spring and autumn are not discussed in detail. 


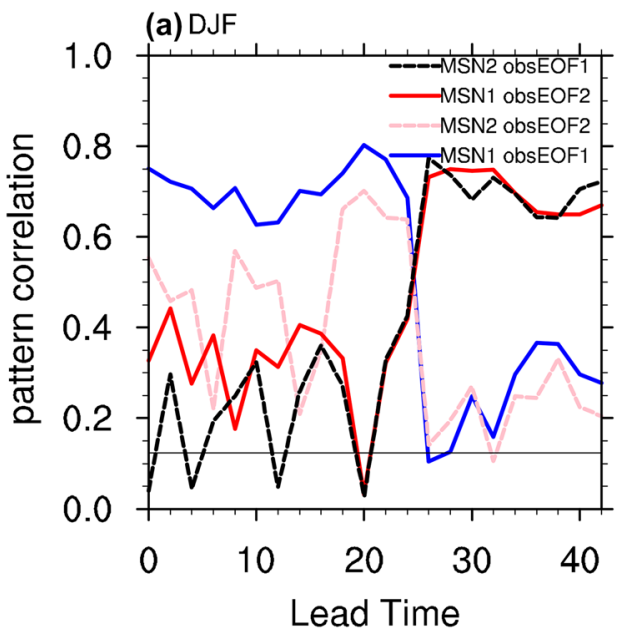

Fig. 7 Pattern similarities between conventional EOFs and the predictable patterns at different leads for a winter and $\mathbf{b}$ spring on 30-60-day time scale. The solid blue line represents the pattern correlation coefficients between the MSN EOF1 pattern and the first observed EOF mode. The dashed pink line represents the pattern correlation coefficients between the MSN EOF2 pattern and the second

During boreal winter, an obvious warm SST center occupies the northwest to Australia where a significant positive OLR center is located, and both centers are significant at all leads (Fig. 10, only LD0 shown). A significant negative OLR center is found over the equatorial IO, which lies $40^{\circ}$ west of the warm SST center. This feature means an out-ofphase relationship over the IO and nearby areas northwest to Australia (Fig. 1) and illustrates the corresponding process between oceans and the atmosphere, stressing atmospheric drive on the oceans. In spring, the regression patterns of both SST and OLR are similar to those in winter, with slightly eastward occupation of the OLR center and weaker SST warming center (figure not shown). At the lower level, strong easterly wind appears over the MC and its nearby areas in winter at all leads, accompanied by weak westerly wind over the equatorial IO. At the higher level, westerly and easterly winds occupy the $\mathrm{MC}$ and the western equatorial IO, respectively, with anticyclonic and cyclonic circulations over the subtropical northern and southern IO, West Australia, and the northwestern Pacific Ocean. In spring, significant cyclonic and anticyclonic circulations occur to the north and south of the strong westerly wind over the equatorial IO, respectively. Strong easterly wind over the eastern MC at the lower level and its counterpart at the higher level can also be identified (figure not shown), which is consistent with the Gill (1980) theory. In addition, at the lower level, the climatological winds are mainly westerly over the equatorial IO and easterly to the east of the MC. The regression of 850$\mathrm{hPa}$ wind discussed above also exhibits weak westerly wind over the equatorial IO and strong easterly wind over the MC, thus accelerating evaporation and favoring the equatorial

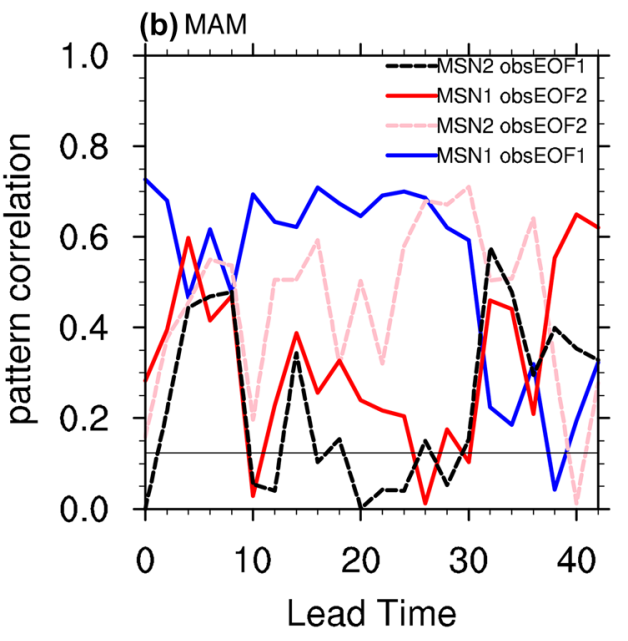

observed EOF mode. The solid red line represents the pattern correlation coefficients between the MSN EOF1 pattern and the second observed EOF mode. The dashed black line represents the pattern correlation coefficients between the MSN EOF2 pattern and the first observed EOF mode. The thin black straight line represents the $95 \%$ confidence level

eastward propagation of subseasonal convective center according to the evaporation-wind feedback mechanism. In short, the most predictable patterns on 30-60-day time scale during the boreal winter half of the year are mainly associated with the eastward propagation of the MJO. Moreover, the regressions of climatic variables resemble the counterparts at LD0 and even at the leads when pattern shifts occur (figure not shown), implying similar climate variations and physical mechanisms for the most predictable patterns.

The patterns of regression are quite different for the summer half of the year. At different leads (Fig. 11, only LD0 shown), cold SST domains including the Arabian Sea, the $\mathrm{BOB}$, the SCS, and the western Pacific are significant. The negative relationship between northern IO SST and PC1 is consistent with the result of $\mathrm{Wu}$ and Cao (2017). The predominant cold SST distribution at different leads favors the land-sea thermal contrast, which is associated with monsoon activity. In addition, the regression of OLR shows an outof-phase distribution compared with the regression of SST. Negative centers occupy the Arabian Sea, the BOB, and the western Pacific where cold SST centers are located. The latitudinal distance between the negative OLR center and the positive SST center favors an out-of-phase meridional distribution of rainfall patterns during summer, and implies a response process from the atmosphere to oceans as well as a northward propagation of subseasonal convective activity. The regressions in autumn are similar to those in summer except for a stronger warm SST center over the eastern equatorial IO and a weaker cold SST center over the western Pacific, which is associated with a later withdrawal of the 

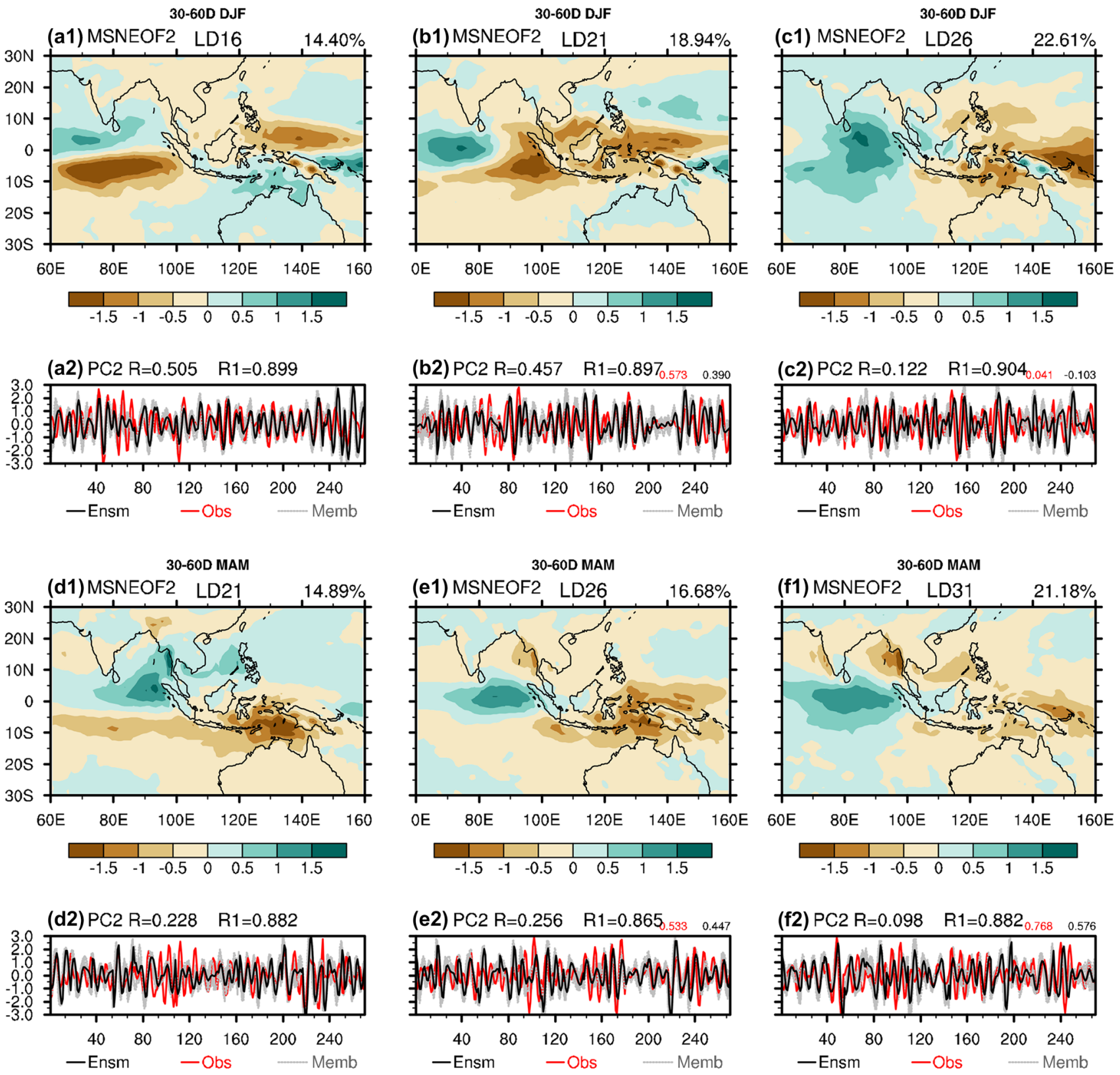

Fig. 8 Second MSN EOF modes and PCs of rainfall (mm/day) predicted by the CFSv2 for lead days of a 16, b 21, and $\mathbf{c} 26$ in winter and $\mathbf{d} 21$, e 26, and $\mathbf{f} 31$ in spring on 30-60-day time scale. The solid black lines represent the PCs of the ensemble means and the dashed grey lines represent the PCs of different ensemble members while the solid red lines represent the PCs that are computed by projecting the observed rainfall onto the spatial distribution of the MSN EOF2. $R$ represents the correlation coefficient between the solid red line and the solid black line and R1 represents the averaged correlation coefficient among ensemble members
Indian monsoon and an earlier withdrawal of the East Asian monsoon as discussed in Sect. 3.

The regression of 850-hPa wind in summer (Fig. 11b) shows obvious cross-equatorial, westerly wind over the northern IO, the Arabian Sea, the BOB, and the SCS. Strong northeasterly wind prevails over the MC and nearby regions at the higher level (Fig. 11d). Such distribution denotes that monsoon circulation exerts a profound influence on the meridional movement of subseasonal convective activity, which mainly propagates northward over the IO and the western Pacific (Wang and Rui 1990). Wind fields are nearly the same in summer and autumn, which mainly show an influence of monsoon 


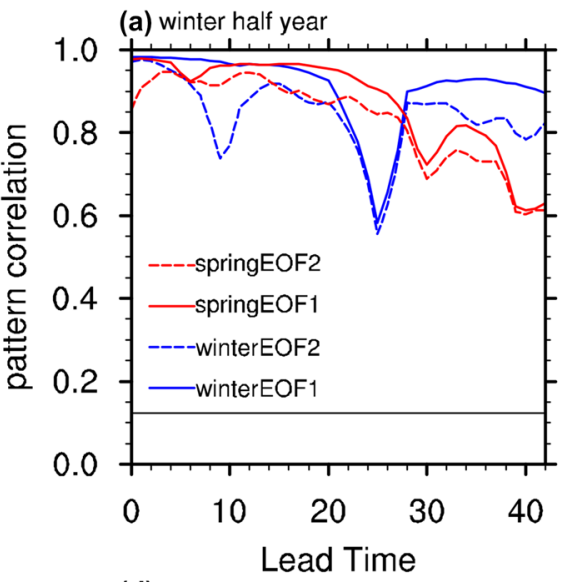

(d) summer half year

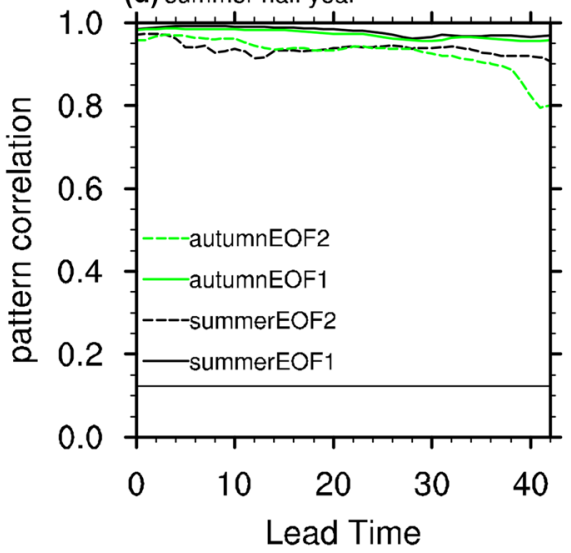

(b) winter half year

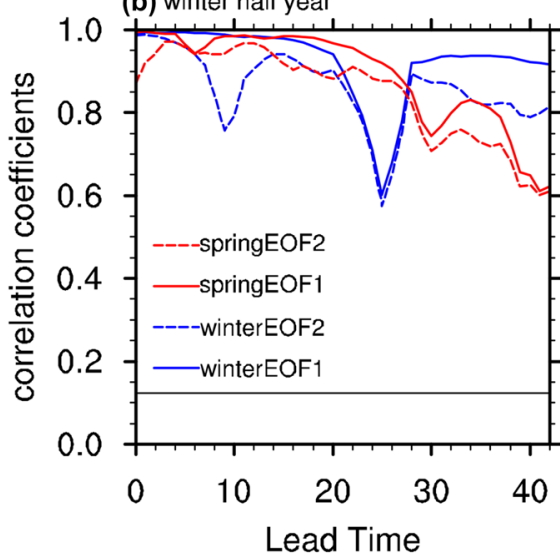

(e) summer half year

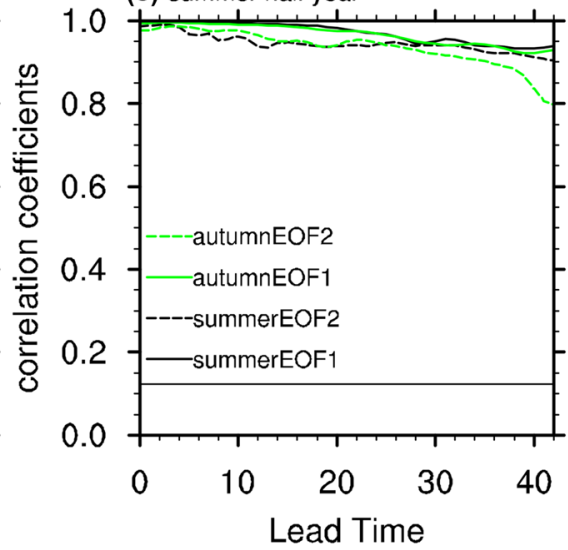

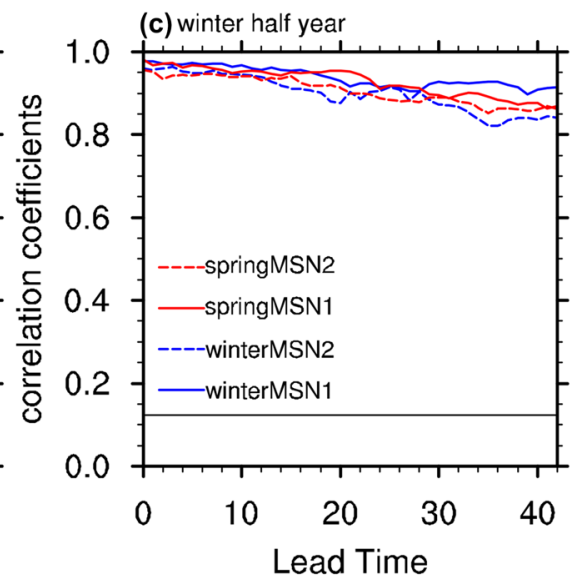

(f) summer half year

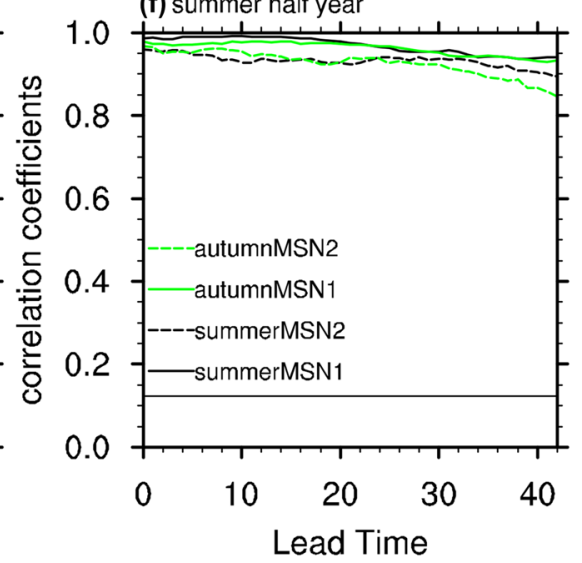

Fig. 9 Averaged pattern correlation coefficients of EOFs (left panel, a, d), averaged correlation coefficients of PCs (middle panel, b, e), averaged correlation coefficients of MSN PCs (right panel, $\mathbf{c}, \mathbf{f}$ ) between different ensemble member and the ensemble mean of rainfall over the Indo-Pacific regions on 30-60-day time scale. The thin black straight line represents the $95 \%$ confidence level (a) LDO

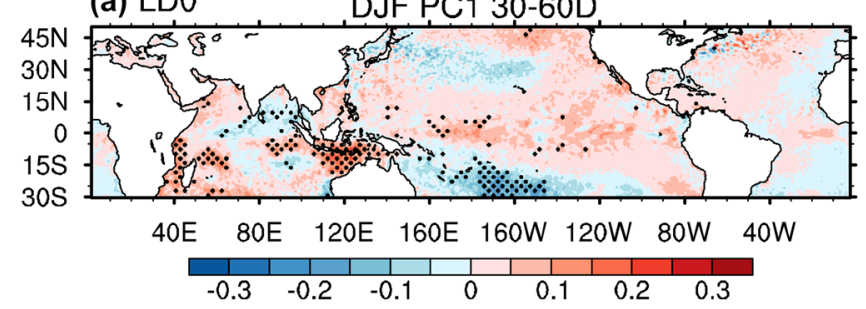

(c) LDO

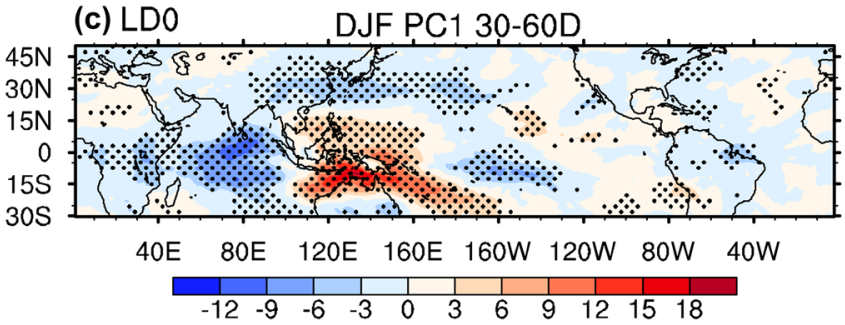

Obs.OLR Reg (b) LDO

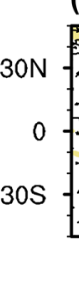

Obs.UV85 Reg

DJF PC1 30-60D

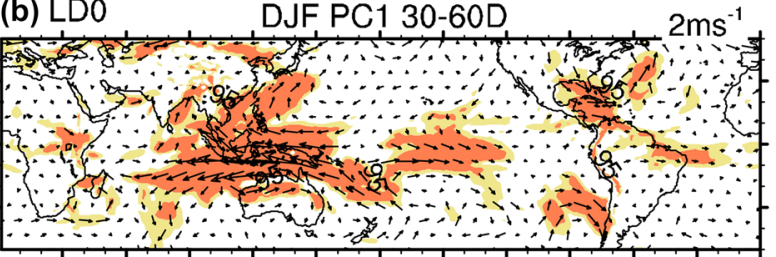

30E 60E 90E 120E150E 180 150WH20W 90W 60W 30W O

(d) LDO

Obs.U20 Reg

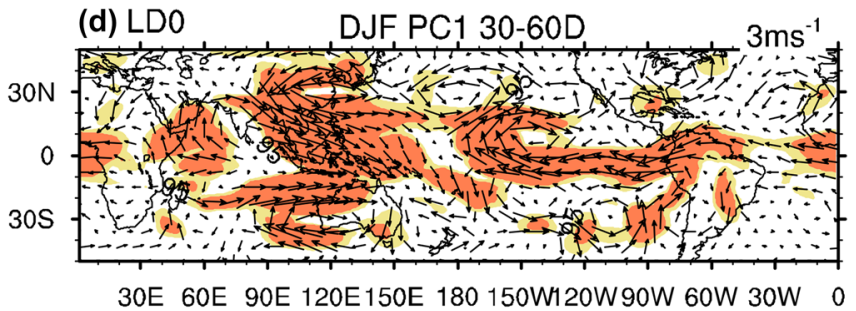

$30 \mathrm{E} 60 \mathrm{E} 90 \mathrm{E} 120 \mathrm{E} 150 \mathrm{E} 180$ 150W120W90W 60W 30W 0

Fig. 10 Regressions of observed a SST, b 850-hPa winds, c OLR, and d 200-hPa winds against ensemble-mean PC1 at LD0 in winter on 30-60day time scale. Scattered dot areas in a, $\mathbf{c}$ and shaded areas (yellow for $90 \%$ ) in $\mathbf{b}, \mathbf{d}$ represent the $95 \%$ confidence level 
(a) LDO

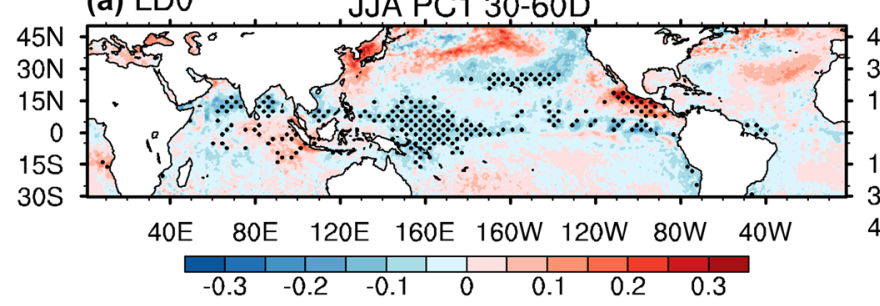

Obs.oLR Reg

(c) LD0

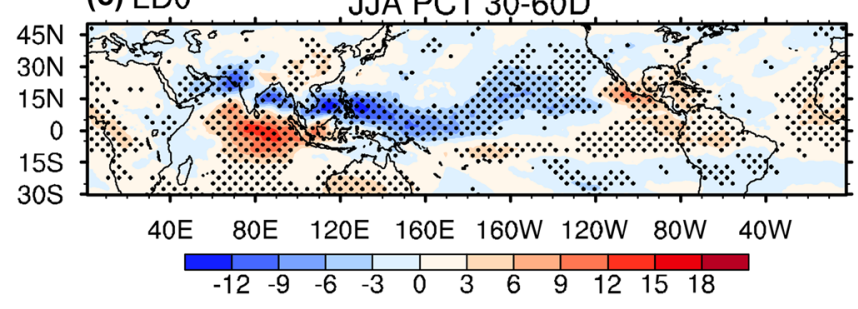

(b) LDO

uns.uvrs keg.

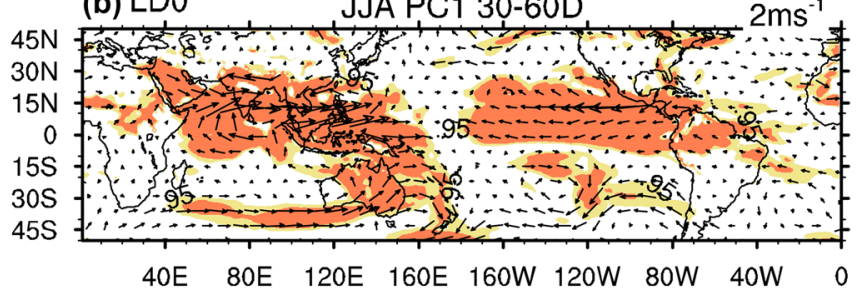

(d) LDO

Obs.Uv20 Reg

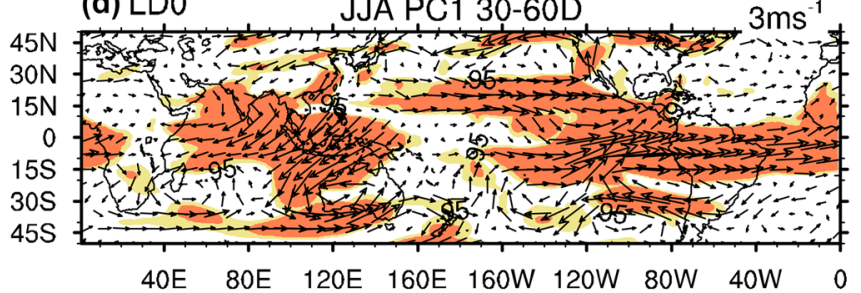

Fig. 11 Same as Fig. 10 but for summer

activity on the predictable patterns during the summer half of the year.

\section{Summary and discussion}

In this study, we have depicted the most predictable patterns of the Indo-Pacific rainfall, by applying a maximized signal-to-noise empirical orthogonal function analysis, on MJO and QBWO time scales. We have also investigated the seasonality of these most predictable patterns and discussed the differences in the patterns and their seasonal features between the MJO and QBWO modes. The variations of large-scale atmospheric circulation associated with the rainfall features have been examined as well.

The most predictable patterns on 30-60-day time scale during boreal winter and spring both show a tropical zonal dipole associated with the eastward propagation of MJO, while the most predictable patterns during summer and autumn show a meridional dipole, which mainly implies a northward propagation of boreal summer ISO. The NCEP CFSv2 well predicts the most predictable patterns for all seasons but with a relatively low skill of about 20 days for summer, which may be associated with the influence of summer monsoon activity. Better skills can be found with lead time around 30 days in winter and the transitional seasons. The zonal dipole for the boreal winter half of the year exhibits opposite distributions over the tropical IO and the surrounding oceanic areas of the MC. This dipole changes into the feature of uniform variation at long leads, characterized by a consistent distribution over the $\mathrm{MC}$ and the nearby areas especially in winter. The shift of predictable patterns during the boreal winter half of the year mainly results from the relatively high spread among ensemble members. For the summer half of the year, the meridional dipole shows opposite features between the tropical belt covering the Arabian Sea, the BOB, the SCS, and the western Pacific and the equatorial belt covering the equatorial IO and the MC.

On 30-60-day time scale, the most predictable patterns during the boreal winter half of the year are associated with the eastward propagation of MJO, while the most predictable patterns during the summer half of the year associated with the northward propagation of the boreal summer ISO. Atmospheric drive on the oceans plays an important role in the pattern distribution, and the corresponding wind fields at both upper and lower levels are consistent with the Gill response in winter and spring. The related circulation during the winter half of the year emphasizes the influence of the evaporation-wind feedback mechanism on subseasonal convective activity. During the summer half of the year, air-sea interaction is still important when the predominant cold SST distribution at all leads favors the land-sea thermal contrast associated with monsoon intensity. Both upper- and lower-level winds exhibit the features of monsoon circulation, which exerts a profound influence on the meridional movement of subseasonal convective activity.

The 10-20-day convective activity shows a relatively smaller contribution to the total variance and is mainly confined to the subtropical regions along the $10^{\circ}-30^{\circ}$ latitudinal band. However, large variance of QBWO can still be found in the Asian summer monsoon region (Kikuchi and Wang 2009; Wang and Zhang 2018). Figure 12 shows the most predictable patterns on 10-20-day time scale during summer. Convective centers are located over the western North Pacific, the SCS, and the BOB. Unlike the 30-60-day 

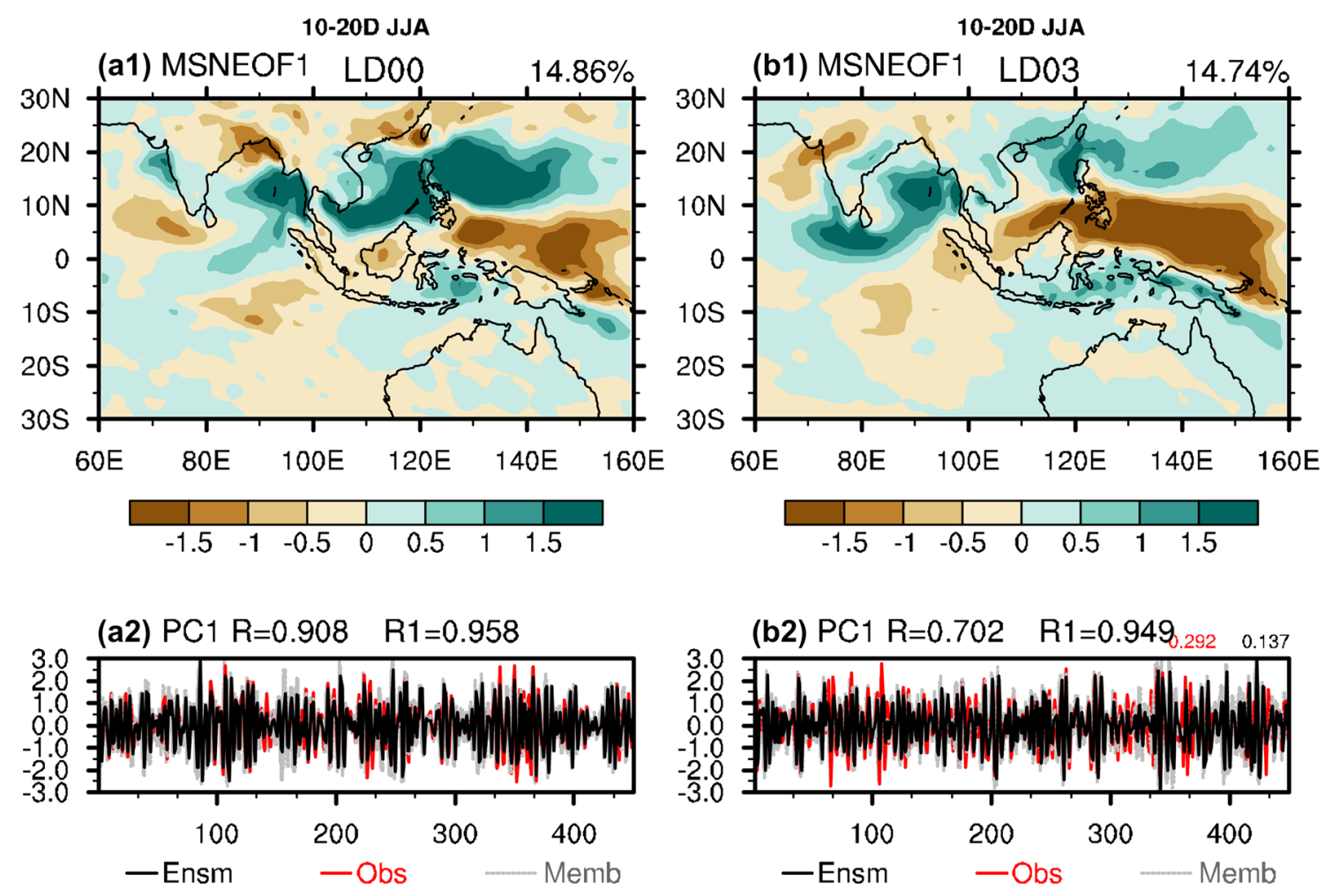

10-20D JJA

(c1) MSNEOF1 LD06
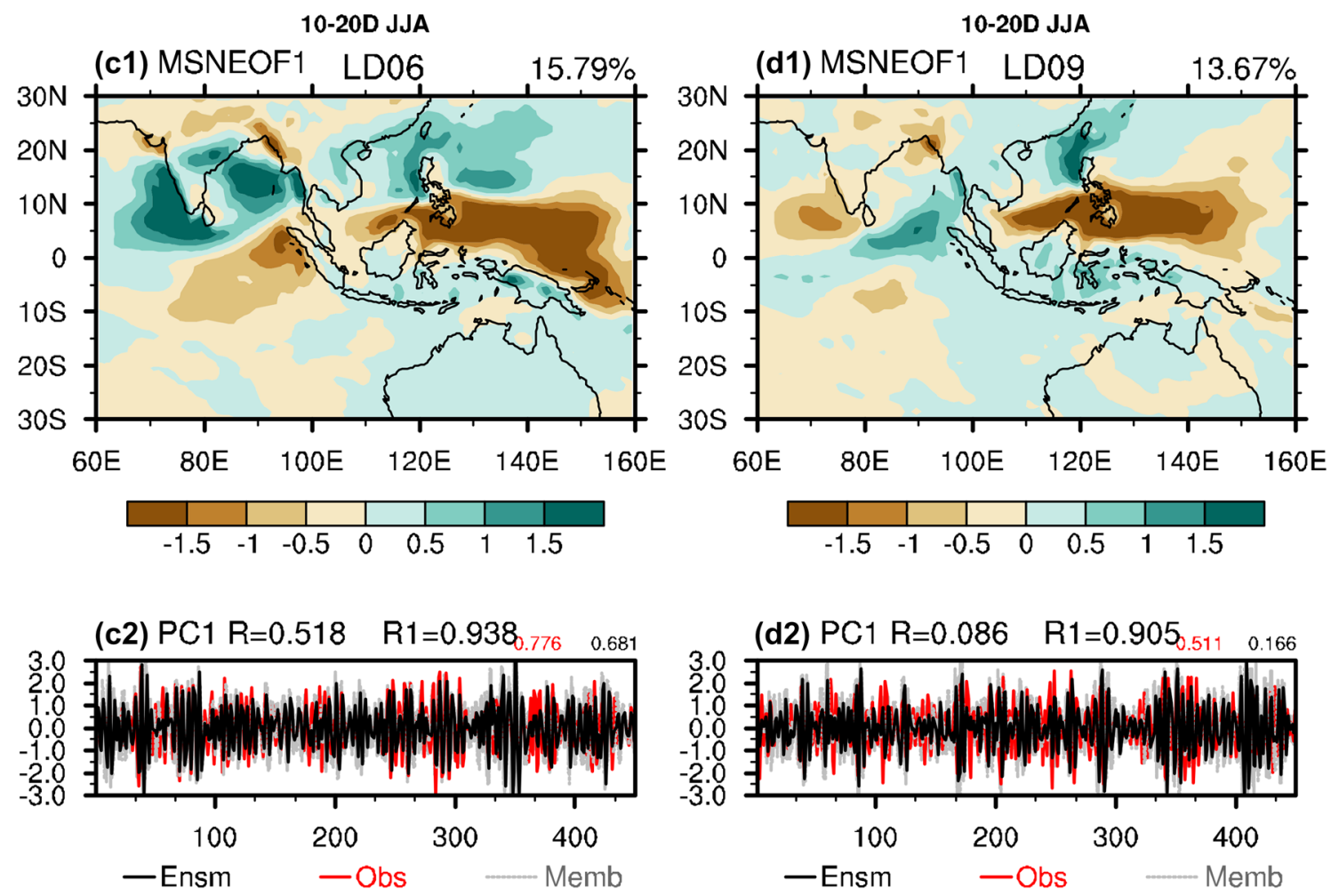

Fig. 12 Same as Fig. 3 but for lead days of 0,3, 6, and 9 in summer and on 10-20-day time scale 


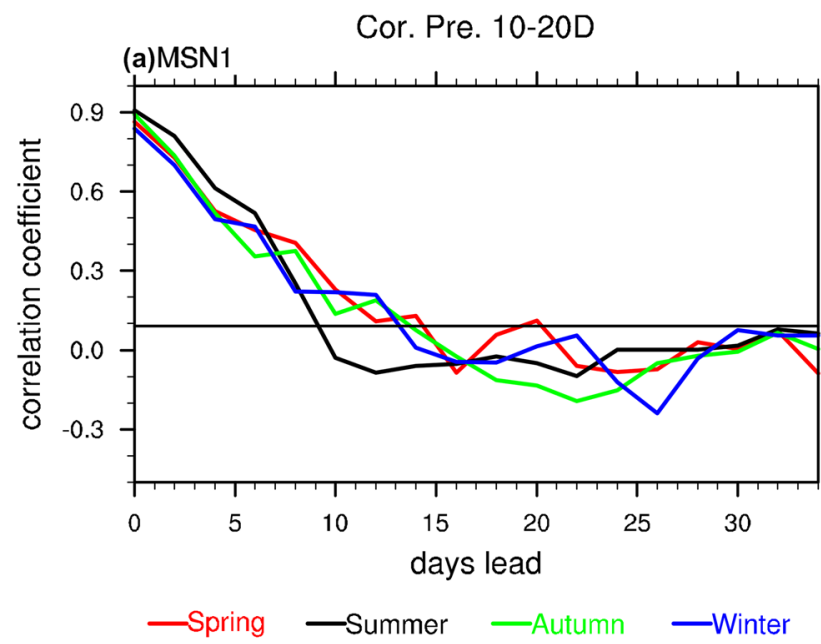

Cor. Pre. 10-20D

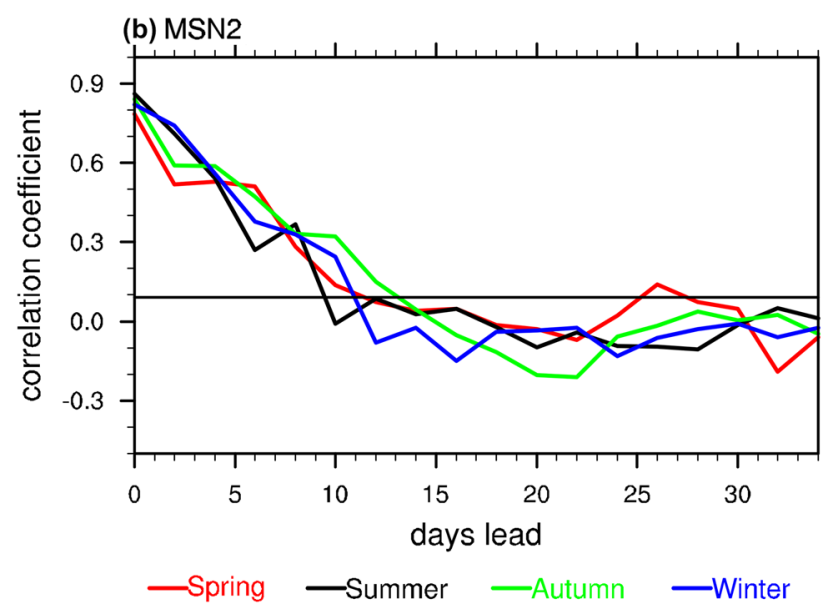

Fig. 13 Correlation coefficients between ensemble-mean PCs and projected PCs (computed by projecting the observed rainfall upon the corresponding MSN EOF modes) for a MSN EOF1 and b MSN EOF2 on 10-20 day time scale. The black straight line represents the correlation coefficients at the $95 \%$ confidence level

patterns, a meridional dipole can be found over the IO and the western Pacific in all seasons (figures not shown), but is most obvious in summer, associated with the QBWO and monsoon activity. Compared with the most predictable patterns on the 30-60-day time scale, the patterns on 10-20-day time scale exhibit conspicuously smaller variance and the skills of its prediction drop quickly with increasing lead time (Fig. 13). Particularly, the NCEP CFSv2 presents the worst skill in summer (with around 10 days) on the 10-20-day predictions for both the most predictable pattern and the second most predictable pattern. In winter and the transitional seasons, the 10-20-day predictions show scattered features and weaker link to large-scale climate variations. In short, higher frequency signals, namely the 10-20-day prediction, provide more challenges compared with the 30-60-day prediction for subseasonal prediction by models, and the 10-20-day regressions of climatic variables during summer show features of monsoon circulations at both upper and lower levels, consistent with the result of Chen and Chen (1993) and of Kikuchi and Wang (2009).

Acknowledgements This study was supported jointly by the National Key Research and Development Program of China (Grants 2018YFC1505801 and 2016YFA0602703), the National Natural Science Foundation of China (Grants 41661144019, 41690123, 41690120 and 41975074), the Jiangsu Collaborative Innovation Center for Climate Change, the Zhuhai Joint Innovative Center for Climate, Environment and Ecosystem, and the CMA Guangzhou Joint Research Center for Atmospheric Sciences.

Open Access This article is licensed under a Creative Commons Attribution 4.0 International License, which permits use, sharing, adaptation, distribution and reproduction in any medium or format, as long as you give appropriate credit to the original author(s) and the source, provide a link to the Creative Commons licence, and indicate if changes were made. The images or other third party material in this article are included in the article's Creative Commons licence, unless indicated otherwise in a credit line to the material. If material is not included in the article's Creative Commons licence and your intended use is not permitted by statutory regulation or exceeds the permitted use, you will need to obtain permission directly from the copyright holder. To view a copy of this licence, visit http://creativecommons.org/licenses/by/4.0/.

\section{References}

Adler RF, Huffman GJ, Chang A, Ferraro R, Xie PP, Janowiak J, Rudolf B, Schneider U, Curtis S, Bolvin D, Gruber A, Susskind J, Arkin P, Nelkin E (2003) The version-2 global rainfall climatology project (GPCP) monthly rainfall analysis (1979-present). J Hydrometeorol 4:1147-1167

Allen MR, Smith LA (1997) Optimal filtering in singular spectrum analysis. Phys Lett 234:419-428

Birch C, Webster S, Peatman SC, Parker DJ, Matthews AJ, Li Y, Hassim MEE (2016) Scale interactions between the MJO and the western Maritime Continent. J Clim 29:2471-2492

Chan JCL, Ai W, Xu J (2002) Mechanisms responsible for the maintenance of the 1998 South China Sea summer monsoon. J Meteorol Soc Jpn 80:1103-1113

Chen TC, Chen JM (1993) The 10-20-day mode of the 1979 Indian monsoon: its relation with the time variation of monsoon rainfall. Mon Weather Rev 121:2465-2482

Chen T, Chen JM (1995) An observational study of the South China Sea monsoon during the 1979 summer: onset and life cycle. Mon Weather Rev 123:2295-2318

Chen JP, Wen ZP, Wu R, Chen ZS, Zhao P (2015) Influences of northward propagating 25-90-day and quasi-biweekly oscillations on eastern China summer rainfall. Clim Dyn 45:105-124

Chen RD, Wen ZP, Lu RY (2016) Evolution of the circulation anomalies and the quasi-biweekly oscillations associated with extreme heat events in Southern China. J Clim 29:6909-6921

Dee DP et al (2011) The ERA-Interim reanalysis: configuration and performance of the data assimilation system. Q J R Meteorol Soc 137:553-597

Duchon CE (1979) Lanczos filtering in one and two dimensions. J App Meteorol 18:1016-1022 
Ek MB, Mitchell KE, Lin Y, Rogers E, Grunmann P, Koren V, Gayno G, Tarpley JD (2003) Implementation of Noah land surface model advances in the National Centers for Environmental Prediction operational mesoscale Eta model. J Geophys Res 108(D22):8851. https://doi.org/10.1029/2002JD003296

Gill AE (1980) Some simple solutions for heat-induced tropical circulation. Q J R Meteorol Soc 106:447-462

Griffies SM, Harrison MJ, Pacanowski RC, Rosati A (2003) A technical guide to MOM4. GFDL Ocean Group, Technical Report 5, NOAA/GFDL, Princeton, p 295

Hannah WM, Maloney ED, Pritchard MS (2015) Consequences of systematic model drift in DYNAMO MJO hindcasts with SP-CAM and CAM5. J Adv Model Earth Syst 7:1051-1074

Hu ZZ, Huang B (2007) The predictive skill and the most predictable pattern in the tropical Atlantic: the effect of ENSO. Mon Weather Rev 135:1786-1806

Huang B (2004) Remotely forced variability in the tropical Atlantic Ocean. Clim Dyn 23:133-152

Huang P, Chou C, Huang R (2011) Seasonal modulation of tropical intraseasonal oscillations on tropical cyclone genesis in the western North Pacific. J Clim 24:6339-6352

Hung C, Hsu HH (2008) The first transition of the Asian summer monsoon, intraseasonal oscillation, and Taiwan Mei-yu. J Clim 21:1552-1568

Jia XL, Yang S (2013) Impacts of the quasi-biweekly oscillation over the western North Pacific on East Asian subtropical monsoon during early summer. J Geophys Res 118:4421-4434

Jia XL, Yang S, Li X, Liu YY, Wang H, Liu XW, Weaver S (2013) Prediction of global patterns of dominant quasi-biweekly oscillation by the NCEP Climate Forecast System version 2. Clim Dyn 41:1635-1650

Jones C (2000) Occurrence of extreme rainfall events in California and relationships with the Madden-Julian Oscillation. J Clim 13:3576-3587

Jones C, Schemm JKE (2000) The influence of intraseasonal variations on medium- to extended-range weather forecasts over South America. Mon Weather Rev 128:486-494

Kajikawa Y, Yasunari T (2005) Interannual variability of the 10-25and 30-60-day variation over the South China Sea during boreal summer. Geophys Res Lett 32:319-325

Kanamori H, Yasunari T, Kuraji K (2013) Modulation of the diurnal cycle of rainfall associated with the MJO observed by a dense hourly rain gauge network at Sarawak, Borneo. J Clim 26:4858-4875

Kikuchi K, Wang B (2009) Global perspective of the quasi-biweekly oscillation. J Clim 22:1340-1359

Krishnamurti T, Ardanuy P (1980) 10 to 20-day westward propagating mode and "breaks in the monsoons". Tellus 32:15-26

Lee HT (2014) Climate Algorithm Theoretical Basis Document (C-ATBD): outgoing longwave radiation (OLR) - daily. NOAA's Climate Data Record (CDR) program, CDRP-ATBD-0526. p 46. http://www1.ncdc.noaa.gov/pub/data/sds/cdr/CDRs/Outgo ing \%20Longwave\%20Radiation\%20-\%20Daily/AlgorithmD escription.pdf.

Lee HT, Gruber A, Ellingson RG, Laszlo I (2007) Development of the HIRS outgoing longwave radiation climate dataset. J Atmos Ocean Tech 24:2029-2047

Liang JY, Yang S, Hu ZZ, Huang B, Kumar A, Zhang Z (2009) Predictable patterns of the Asian and Indo-Pacific summer rainfall in the NCEP CFS. Clim Dyn 32:989-1001

Liang J, Wu LG, Ge XY, Wu CC (2011) Monsoonal influence on typhoon Morakot (2009). Part II: numerical study. J Atmos Sci 68:2222-2235

Liebmann B, Smith CA (1996) Description of a complete (interpolated) outgoing longwave radiation dataset. Bull Am Meteorol Soc 77:1275-1277
Lin H, Brunet G, Derome J (2008) Forecast skill of the MaddenJulian oscillation in two Canadian atmospheric models. Mon Weather Rev 136:4130-4149

Liu XW, Yang S, Li JL, Jie WH, Huang L, Gu WZ (2015) Subseasonal predictions of regional summer monsoon rainfall over tropical Asian oceans and land. J Clim 28:9583-9605

Lu JM, Ju JH, Ren JZ, Gan WW (2012) The influence of the Madden-Julian oscillation activity anomalies on Yunnan's extreme drought of 2009-2010. Sci China (Earth Sci) 55:98-112

Madden RA, Julian PR (1971) Detection of a 40-50 day oscillation in the zonal wind in the tropical Pacific. J Atmos Sci 28:702-708

Madden RA, Julian PR (1972) Description of global scale circulation cells in the tropics with $40-50$ day period. J Atmos Sci 29:1109-1123

Maloney ED, Jiang X, Xie S, Benedict JJ (2014) Process-oriented diagnosis of East Pacific warm pool intraseasonal variability. J Clim 27:6305-6324

Moorthi S, Pan HL, Caplan P (2001) Changes to the 2001 NCEP operational MRF/AVN global analysis/forecast system. NWS Tech Proced Bull 484:1-14. http://www.nws.noaa.gov/om/tpb/484.htm

Neena JM, Lee JY, Waliser D, Wang B, Jiang X (2014) Predictability of the Madden-Julian oscillation in the intraseasonal variability hindcast experiment (ISVHE). J Clim 27:4531-4543

Paegle JN, Byerle LA, Mo KC (2000) Intraseasonal modulation of South American summer rainfall. Mon Weather Rev 128:837-850

Rashid HA, Hendon HH, Wheeler MC, Alves O (2011) Prediction of the Madden-Julian oscillation with the POAMA dynamical prediction system. Clim Dyn 36:649-661

Rauniyar S, Walsh KJE (2010) Scale interaction of the diurnal cycle of rainfall over the Maritime Continent and Australia: Influence of the MJO. J Clime 24:325-348

Reichler T, Roads J (2005) Long-range predictability in the tropics. Part II: 30-60 day variability. J Clim 18:634-649

Reynolds RW, Smith TM, Liu C, Chelton DB, Casey KS, Schlax MG (2007) Daily high-resolution blended analyses for sea surface temperature. J Clim 20:5473-5496

Saha S, Nadiga S, Thiaw C et al (2006) The NCEP climate forecast system. J Clim 19:3483-3517

Saha SK, Pokhrel S, Salunke K, Dhakate A, Chaudhari HS, Rahaman H, Sujith K, Hazra A, Sikka DR (2016) Potential predictability of Indian summer monsoon rainfall in NCEP CFSv2. J Adv Model Earth Syst 8:96-120. https://doi.org/10.1002/2015MS000542

Seo KH, Schemm JKE, Jones C, Moorthi S (2005) Forecast skill of the tropical intraseasonal oscillation in the NCEP GFS dynamical extended range forecasts. Clim Dyn 25:265-284

Seo KH, Schemm JKE, Wang W, Kumar A (2007) The boreal summer intraseasonal oscillation simulated in the NCEP Climate Forecast System (CFS): the effect of sea surface temperature. Mon Weather Rev 135:1807-1827

Seo KH, Wang W, Gottschalck J, Zhang Q, Schemm JKE, Higgins WR, Kumar A (2009) Evaluation of MJO forecast skill from several statistical and dynamical forecast models. J Clim 22:2372-2388

Sperber KR, Slingo JM, Inness PM, Lau KM (1997) On the maintenance and initiation of the intraseasonal oscillation in the NCEP/ NCAR reanalysis and in the GLA and UKMO AMIP simulations. Clim Dyn 13:769-795

Turner AG, Inness PM, Slingo JM (2005) The role of the basic state in the ENSO-monsoon relationship and implications for predictability. Q J R Meteorol Soc 131:781-804

Venzke S, Allen MR, Sutton RT, Rowell DP (1999) The atmospheric response over the North Atlantic to decadal changes in sea surface temperature. J Clim 12:2562-2584

Waliser DE, Lau KM, Stern W, Jones C (2003) Potential predictability of the Madden-Julian Oscillation. Bull Am Meteorol Soc $84: 33-50$ 
Wang B, Rui H (1990) Synoptic climatology of transient tropical intraseasonal convection anomalies: 1975-1985. Meteorol Atmos Phys 44:43-61

Wang B, Xie XS (1997) A model for the boreal summer intraseasonal oscillation. J Atmos Sci 54:72-86

Wang X, Zhang GJ (2018) Evaluation of the Quasi-Biweekly Oscillation over the South China Sea in early and late summer in CAM5. J Clim 32:69-84

Wang G, Kleeman R, Smith N, Tseitkin F (2001) The BMRC coupled general circulation model ENSO forecast system. Mon Weather Rev 130:975-991

Wang B, Lee JY, Kang IS, Shukla J, Kug JS, Kumar A (2008) How accurately do coupled climate models predict the leading modes of Asian-Australian monsoon interannual variability? Clim Dyn 30:605-619

Wang B et al (2009) Multi-scale climate variability of the South China Sea monsoon: a review. Dyn Atmos Oceans 47:15-37

Wang WQ, Hung M, Weaver SJ, Kumar A, Fu XH (2014) MJO prediction in the NCEP climate forecast system version 2. Clim Dyn 42:2509-2520

Wen M, Yang S, Vintzileos A, Higgins W, Zhang R (2012) Impacts of model resolutions and initial conditions on predictions of the Asian summer monsoon by the NCEP Climate Forecast System. Weather Forecast 27:629-646

Wheeler MC, Hendon HH (2004) An all-season real-time multivariate MJO index: development of an index for monitoring and prediction. Mon Weather Rev 132:1917-1932

Wu R, Cao X (2017) Relationship of boreal summer 10-20-day and 30-60-day intraseasonal oscillation intensity over the tropical western North Pacific to tropical Indo-Pacific SST. Clim Dyn 48:3529-3546
Yang J, Wang B (2008) Anticorrelated intensity change of the quasibiweekly and 30-50-day oscillations over the South China Sea. Geophys Res Lett 35:797-801

Yang S, Jiang Y, Zheng D, Higgins W, Zhang Q, Kousky VE, Wen M (2009) Variations of U.S. regional rainfall and simulations by the NCEP CFS: focus on the Southwest. J Clim 22:3211-3231

Zhang T, Huang BH, Yang S, Laohalertchai C (2018a) Seasonal dependence of the predictable low-level circulation patterns over the tropical Indo-Pacific domain. Clim Dyn 50:4263-4284

Zhang T, Huang BH, Yang S, Kinter JL (2018b) Predictable patterns of the atmospheric low-level circulation over the Indo-Pacific region in project minerva: seasonal dependence and intra-ensemble variability. J Clim 31:8351-8379. https://doi.org/10.1175/ JCLI-D-17-0577.1

Zhou W, Chan J (2005) Intraseasonal oscillations and the South China Sea summer monsoon onset. Int J Climatol 25:1585-1609

Zhu J, Huang BH, Kumar A, Kinter JLI (2015) Seasonality in prediction skill and predictable pattern of tropical Indian Ocean SST. J Clim 28:801-809

Zuo Z, Yang S, Hu ZZ, Zhang RH, Wang WQ, Huang BH, Wang F (2013) Predictable patterns and predictive skills of monsoon rainfall in Northern Hemisphere summer in NCEP CFSv2 reforecasts. Clim Dyn 40:3071-3088

Publisher's Note Springer Nature remains neutral with regard to jurisdictional claims in published maps and institutional affiliations. 